\title{
Integração dos métodos geofísicos de eletrorresistividade, polarização induzida e eletromagnético Aterro Sanitário de Guaratuba-PR
}

Integration of geophysical methods of resistivity, induced polarization and electromagnetic Landfill Guaratuba-PR

\author{
RAFAEL ESPINDOLA CANATA ${ }^{1}$, FRANCISCO JOSÉ FONSECA FERREIRA ${ }^{1}$, RODOILTON \\ STEVANATO $^{1}$, FÁBIO AUGUSTO DA SILVA SALVADOR ${ }^{2}$, ODERSON ANTONIO DE SOUZA \\ FILHO $^{3}$
}

\begin{abstract}
${ }^{1}$ Universidade Federal do Paraná - UFPR, Paraná, ${ }^{2}$ Setor Técnico Científico da Polícia Federal do Paraná- SETEC, ${ }^{3}$ Serviço Geológico do Brasil-CPRM, -rafaelcanata@gmail.com,francisco.ferreira@ufpr.br,rodoilton@ufpr.br,salvador.fass@dpf.gov.br, oderson.souza@cprm.gov.br
\end{abstract}

\begin{abstract}
Resumo
Este trabalho demonstra a aplicação dos métodos geofísicos de eletrorresistividade (ER), polarização induzida (IP) e eletromagnético (EM) no aterro sanitário de Guaratuba, litoral do Estado do Paraná. Os objetivos principais da pesquisa foram delimitar a pluma de contaminação em subsuperfície e indicar áreas susceptíveis à contaminação. A área do aterro sanitário é representada por granitos do Proterozóico Inferior e sedimentos recentes do Quaternário. Os dados de ER e IP foram obtidos nas áreas internas e adjacentes aos depósitos atual e futuro, através de caminhamento elétrico $2 \mathrm{D}$, arranjo dipolo-dipolo $(\mathrm{AB}=\mathrm{MN}=20 \mathrm{~m})$, além de uma sondagem elétrica vertical (SEV) $(\mathrm{AB} / 2=150 \mathrm{~m})$, no centro do depósito atual. O levantamento eletromagnético (EM) foi executado nos mesmos locais das linhas de ER e IP, no modo dipolo vertical, bobinas espaçadas de $20 \mathrm{~m}$ e $40 \mathrm{~m}$ e intervalo de amostragem de $10 \mathrm{~m}$. Os resultados obtidos principalmente pelos métodos ER e EM permitiram caracterizar os granitos $(>1000 \mathrm{Ohm} . \mathrm{m} ;<14 \mathrm{mS} / \mathrm{m})$, os sedimentos recentes (entre 800-600 Ohm.m; $<14 \mathrm{mS} / \mathrm{m}$ ) e áreas possivelmente contaminadas $(<50 \mathrm{Ohm} . \mathrm{m} ;>20 \mathrm{mS} / \mathrm{m})$. Tais resultados possibilitaram ainda sugerir tratos suspeitos de contaminação $(50-70 \mathrm{Ohm} . \mathrm{m} ; 15-20 \mathrm{mS} / \mathrm{m})$ e não contaminados $(>70$ Ohm.m; < $15 \mathrm{mS} / \mathrm{m}$ ), além de estimar em $30 \mathrm{~m}$ a espessura do aterro, em correspondência a interpretação da SEV. Os resultados de IP não foram satisfatórios, possivelmente devido à sua sensibilidade a resíduos metálicos no depósito.
\end{abstract}

Palavras-chave: Métodos geofísicos; aterro sanitário de Guaratuba; contaminação

\begin{abstract}
This paper illustrates the applications of the geophysical methods of electrical resistivity (ER), induced polarization (IP) and inductive electromagnetic (EM) in the sanitary landfill of Guaratuba city, at the coast of Paraná State. The main objectives of the research were to delineate the contamination plume in the subsurface and to indicate susceptible areas to contamination. The area of the landfill is represented by granites of the Lower Proterozoic and recent Quaternary sediments. The ER and IP data were obtained in internal and adjacent areas of the current and the future landfills, using $2 D$ resistivity section with the dipole-dipole array $(A B=M N=20 \mathrm{~m})$, as well as a vertical electrical sounding (VES) $(A B / 2=150 \mathrm{~m})$ in the center of the current deposit. The electromagnetic survey (EM) was conducted in the same locations of ER and IP lines in the vertical dipole mode, with coil separations of $20 \mathrm{~m}$ and $40 \mathrm{~m}$ and $10 \mathrm{~m}$ sample interval. The results obtained by the ER and EM methods characterized the granites (> 1000 ohm.m; $<14 \mathrm{mS} / \mathrm{m})$, recent sediment between $800-600 \mathrm{Ohm} . \mathrm{m} ;<14 \mathrm{mS} / \mathrm{m})$ and possibly contaminated areas $(<50 \mathrm{ohm} \mathrm{m} ;$ $>20 \mathrm{mS} / \mathrm{m})$. Yet it is suggested a differentiation between suspected plume-contaminated sectors (50-70 Ohm $\mathrm{m} ; 15-20 \mathrm{mS} / \mathrm{m})$ and not contaminated sectors $(>70$ Ohm.m; $<15 \mathrm{mS} / \mathrm{m})$. The maximum thickness of the landfill is estimated in $30 \mathrm{~m}$, in correspondence with the SEVs interpretations. The IP results were not satisfactory, probably because of the sensitivity ER system to metals objects present in the waste.
\end{abstract}

Keywords: Geophysical methods, landfill of Guaratuba, contamination

\section{Introdução}

Os municípios brasileiros se deparam com um grande problema de ordem ambiental, social e econômica que está relacionado com a disposição, a redução, a reciclagem, a reutilização e o tratamento eficiente dos resíduos sólidos urbanos (RSU). A degradação deste material em um aterro sanitário ocorre por processos físicos, químicos e biológicos e resultam na geração do percolado (chorume) e de gases (Boscov, 2012). O chorume e seus compostos secundários, quando não tratados ou controlados adequadamente, podem se infiltrar através da ação das águas pluviais no subsolo, causando danos ao ambiente.

Para mitigar possíveis problemas ocasionados pelo manejo inadequado dos resíduos sólidos foi 
promulgada no ano de 2010 a Lei $\mathrm{n}^{\mathrm{o}}$ 12.305/10, denominada Plano Nacional de Resíduos Sólidos (PNRS). Esta lei prevê a redução na produção de resíduos sólidos, o reaproveitamento e a disposição adequada em caso de RSU não recicláveis, além de instituir três principais metas: fechamento de todos os lixões até agosto de 2014, destinação apenas de rejeitos[ Rejeitos: resíduos sólidos que, depois de esgotadas todas as possibilidades de tratamento e recuperação por processos tecnológicos disponíveis e economicamente viáveis, não apresentem outra possibilidade que não a disposição final ambientalmente adequada (PNRS, 2010).] para o aterro e uma logística reversa [Logística reversa: significa instrumento de desenvolvimento econômico e social, caracterizado por um conjunto de ações, procedimentos e meios destinados a viabilizar a coleta e a restituição dos resíduos sólidos ao setor empresarial, para reaproveitamento, em seu ciclo ou em outros ciclos produtivos, ou outra destinação final ambientalmente adequada (PNRS, 2010)].

No intuito de auxiliar as investigações de cunho ambiental, os métodos geofísicos, enquanto técnicas de investigação indireta são comumente aplicados e constituem uma alternativa para mapear/diagnosticar áreas passíveis de contaminação (Moreira \& Braga, 2009). A aplicação da geofísica reduz a obtenção de dados diretos, por exemplo, através de perfurações, além de permitir análises temporais e espaciais em detalhe (Elis, 1999).

Nesta pesquisa foram utilizados os métodos geofísicos de eletrorresistividade, polarização induzida (domínio do tempo) e eletromagnético, com o objetivo principal de delinear a possível pluma de contaminação do aterro sanitário de Guaratuba-PR, em convênio com o Setor Técnico-Científico (SETEC) do Departamento de Polícia Federal do Estado do Paraná (DPF-PR) e o Departamento Nacional de Produção Mineral (DNPM). Estudos disponíveis na literatura, como os de Stevanato et al. (2003), Gallas et al. (2005), Fachin et al. (2007), Moreira et al. (2007), Moura e Malagutti Filho (2007); Laureano \& Shirawa (2008), Ustra (2008), dentre outros, foram realizados nesse contexto.

\section{Localização e Histórico}

O antigo lixão de Guaratuba, localizado no litoral do Estado do Paraná (Figura 1), foi instalado provavelmente no ano de 1989 (gerente Élcio da Veiga, informação verbal) e o descarte de resíduos sólidos perdurou por aproximadamente dez anos, sem nenhuma impermeabilização em sua base.

Inicialmente, os resíduos sólidos foram descartados na porção setentrional, correspondente ao depósito atual (Figura 1). Todavia, uma menor quantidade de resíduo (cerca de 1,5 $\mathrm{m}$ de espessura) foi disposta na porção meridional (Figura. 1), coincidente com o depósito futuro ou lote 2 (gerente Élcio da Veiga, informação verbal). Obras de terraplanagem foram realizadas no antigo lixão, para adequá-lo ao futuro aterro sanitário de Guaratuba (Figuras 2A, 2B, 2C e 2D).

\section{Contexto Geológico}

A área de estudo (Figura 3) é caracterizada por rochas do embasamento cristalino, representadas pelo Complexo Gnáissico-Migmatítico Costeiro, do Proterozóico Inferior, além de sedimentos recentes do Quaternário, pertencentes à planície costeira (Mineropar, 2001).

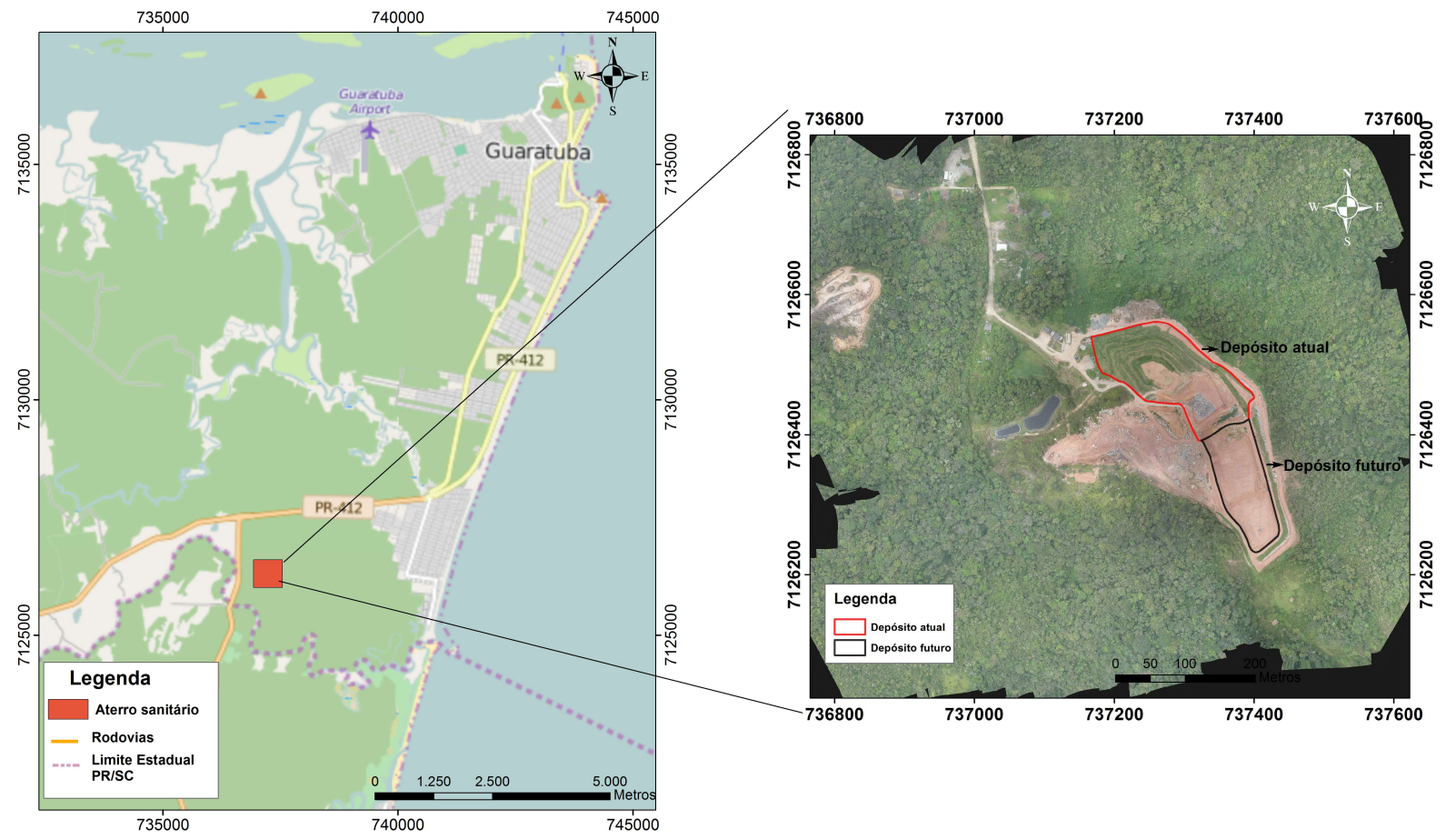

Figura 1 - Mapa do aterro sanitário de Guaratuba-PR indicando a localização dos depósitos atual e futuro (Google Earth, 2009 e imagem VANT, 2014). 


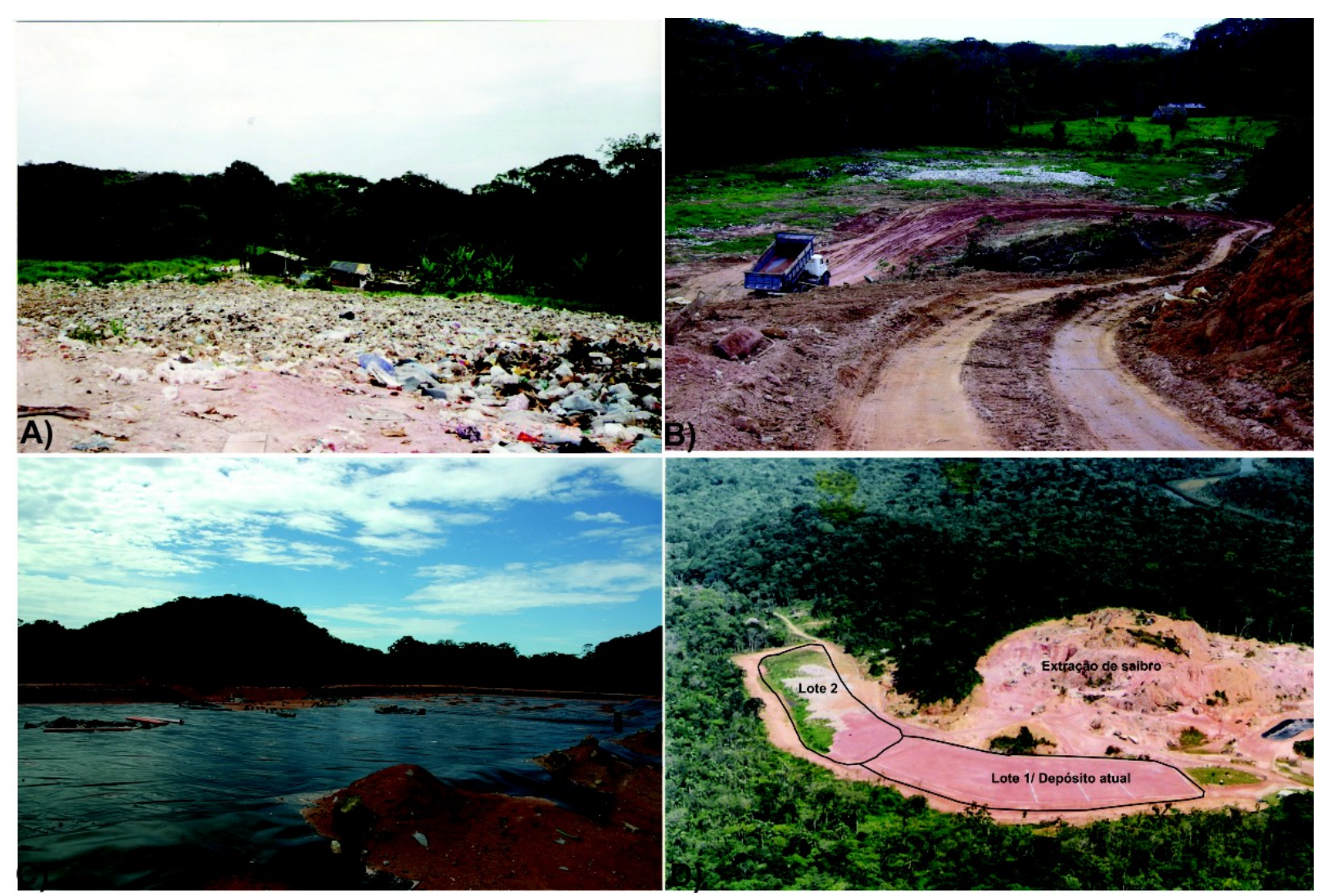

Figura 2 - Fotos do aterro sanitário de Guaratuba: A) Antigo lixão; B) Obra de readequação; C) Manta geotêxtil do aterro futuro (lote2); D) Visão panorâmica do aterro sanitário em fase de construção (fotos cedidas pelo gerente Élcio da Veiga).

O embasamento da área é caracterizado por granitos leucocráticos, com textura equigranular a inequigranular, composto por microclínio, quartzo, oligoclásio/andesina e biotita, em parte recobertos pelos sedimentos arenosos do Quaternário (Figura 3A). Os granitos (Figura 3C) afloram em núcleos maciços e blocos erráticos de tamanhos variados, em contato com produtos de alteração intempérica (Figura 3B), predominando nas cotas mais altas da área de estudo (Góis,1997). Os sedimentos do Quaternário (Figura 3D) são normalmente argilo-arenosos, coloração avermelhada a acinzentada, granulometria fina a média, arredondados e bem selecionados, com intercalações de cerca de $1 \mathrm{~m}$ de argilas brancas.

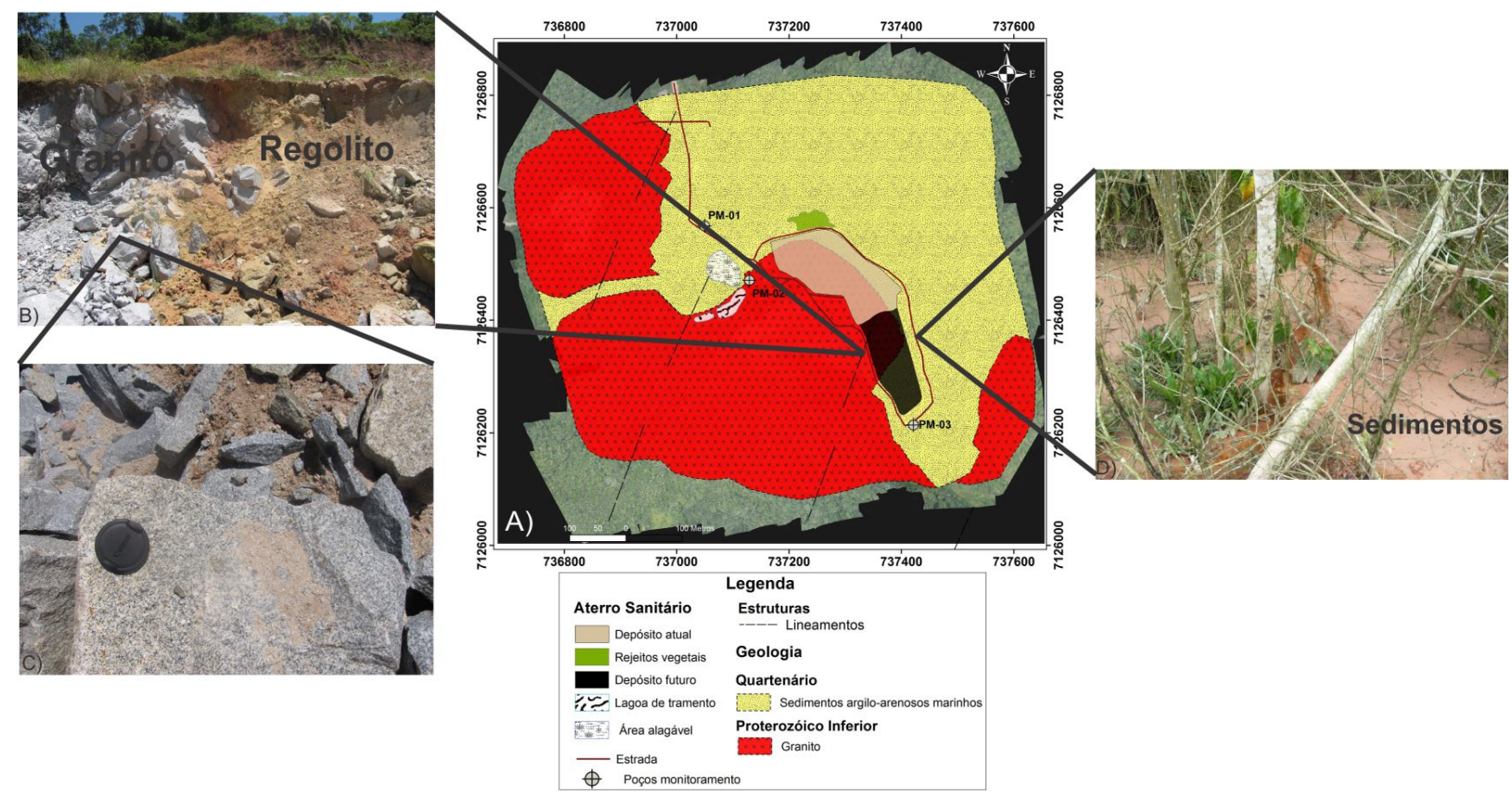

Figura 3 - A) Mapa geológico simplificado da área de estudo (modificado de Góis, 1997); B) Contato regolito/granito; C) Granito equigranular fino; D) Sedimentos recentes da porção leste do depósito. 


\section{Princípios dos Métodos Geofísicos}

O método da eletrorresistividade é baseado na injeção de uma corrente (I) no solo, através de dois eletrodos (A e B), e na medida da diferença de potencial $(\Delta \mathrm{V})$ em outros dois eletrodos $(\mathrm{M} \mathrm{e} \mathrm{N})$, os quais são denominados de potencial. Desta forma é possível calcular a resistividade aparente ( $\rho$ a), dada em Ohm.m.

A resistividade aparente ( $\rho$ a) é um dos conceitos de maior importância na prospecção geoelétrica (Orellana, 1972). É uma função que depende da distribuição da resistividade em cada ponto do semiespaço, da disposição geoelétrica em subsuperfície e do arranjo geométrico dos eletrodos.

(1):

A resistividade aparente ( $\rho$ a) é dada pela equação

$$
\rho a=k \cdot \frac{\Delta V}{I}(1)
$$

onde:

$\rho \mathrm{a}=$ resistividade aparente em Ohm.m;

$\mathrm{k}=$ fator geométrico;

$\Delta \mathrm{V}=$ diferença de potencial em $\mathrm{mV} ; 14$

$\mathrm{I}=$ corrente elétrica em $\mathrm{mA}$.

O fator geométrico $(\mathrm{k})$ depende apenas da disposição dos eletrodos, e pode ser calculado pela equação (2):

$$
k=\frac{2 \pi}{\left(\frac{1}{A M}\right)-\left(\frac{1}{B M}\right)-\left(\frac{1}{A N}\right)+\left(\frac{1}{B N}\right)}
$$

onde:

$\mathrm{k}$ = fator geométrico;

$\mathrm{AM}=$ distância $(\mathrm{m})$ entre os eletrodos $\mathrm{A}$ e $\mathrm{M}$;

$\mathrm{BM}=$ distância $(\mathrm{m})$ entre os eletrodos $\mathrm{B}$ e $\mathrm{M}$;

$\mathrm{AN}=$ distância $(\mathrm{m})$ entre os eletrodos $\mathrm{A}$ e $\mathrm{N}$;

$\mathrm{BN}=$ distância $(\mathrm{m})$ entre os eletrodos $\mathrm{B}$ e N;

A polarização induzida (IP) no domínio do tempo é caracterizada pelo decaimento de uma pequena voltagem $(\mathrm{mV})$, após a interrupção de uma corrente contínua aplicada no solo, resultando na medida da cargabilidade global aparente (Ma) do meio investigado, dada em $\mathrm{mV} / \mathrm{V}$. A voltagem primária $(\mathrm{V})$ é definida como a diferença de potencial registrada enquanto a corrente circula no terreno. Há dois tipos de polarização induzida, a eletrônica (minerais metálicos e grafita) e a de membrana (argilominerais) (Reynolds, 2003). A polarização induzida é representada pela integral da área sob a curva de decaimento, entre dois tempos t1 e t2, após a interrupção da corrente, normalizado pela voltagem primária (V). Sendo assim, a cargabilidade aparente (Ma) é medida de acordo com a equação 3 :

$$
M_{a}=\frac{1}{V_{o}} \int_{t_{1}}^{t_{2}} V_{t} d t(3)
$$

onde:

$\mathrm{Ma}=$ cargabilidade aparente;

$\mathrm{V}=$ voltagem primária;

t 1 e $\mathrm{t} 2$ = intervalo de tempo do decaimento.

Nesta pesquisa foram empregadas as técnicas de caminhamento elétrico (CE) e sondagem elétrica vertical (SEV). O CE é utilizado para investigar variações laterais e verticais de resistividade/IP (2D), normalmente através do arranjo dipolo-dipolo, enquanto a SEV é empregada para averiguar variações verticais de resistividade/IP (1D).

No arranjo dipolo-dipolo o espaçamento (x) entre os eletrodos de corrente $(\mathrm{AB})$ e de potencial $(\mathrm{MN})$ é o mesmo, ou seja, $\mathrm{x}=\mathrm{AB}=\mathrm{MN}$ (Figura 4). Quando a distância $\mathrm{R}$ entre os eletrodos de corrente e de potencial aumenta, há um incremento na profundidade dos níveis (n) de investigação (Loke, 2004). O posicionamento de cada ponto de medida nos vários níveis (n) é dado pela intersecção entre as linhas que partem do centro dos eletrodos de corrente $(\mathrm{AB})$ e dos eletrodos de potencial $(\mathrm{MN})$, formando ângulos de $45^{\circ}$ (Hallof, 1957), conforme a Figura 4. 


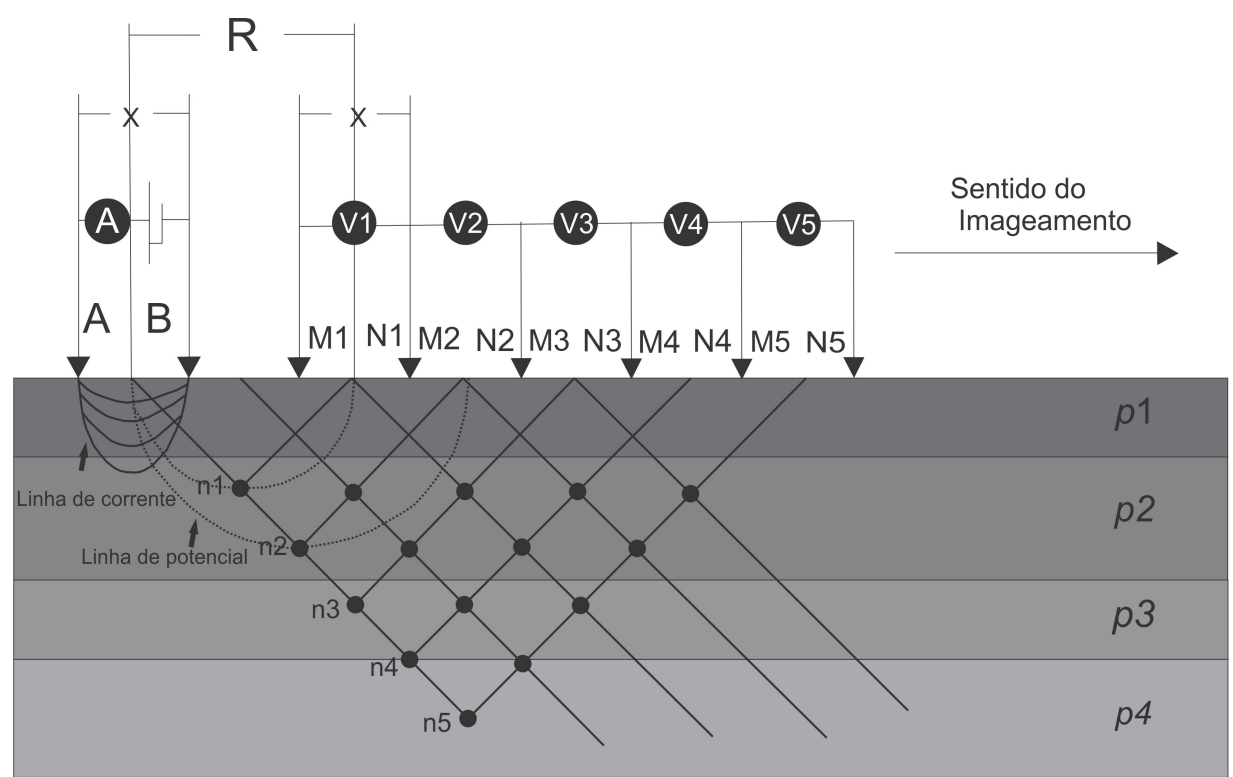

Legenda
A,B eletrodos de corrente
M,N eletrodos de potencial
X abertura do dipolo
R separação do dipolo
p1 a p4 resistividade das camadas
A amperímetro
V1 aoltímetro
n1 a n5 níveis de investigação
- pontos de investigação

Figura 4 - Arranjo dipolo-dipolo indicando os eletrodos de corrente (AB), os de potencial (MN), as linhas de fluxo de corrente e de equipotencial ao interceptar uma pluma de contaminação (modificado Bortolin, 2009).

$\mathrm{Na}$ figura 5 estão representados os eletrodos de corrente $(\mathrm{AB})$ e os de potencial $(\mathrm{MN})$ de uma sondagem elétrica vertical (SEV). No arranjo Schlumberger, utilizado na pesquisa, os eletrodos de corrente (AB) são sucessivamente afastados, enquanto os de potencial $(\mathrm{MN})$ permanecem fixos, até que não seja mais possível ler as diferenças de potencial, decorrentes da grande separação dos eletrodos A e B, pelo que o espaçamento MN é aumentado. Desta forma, para cada posição, as leituras são realizadas na projeção do ponto central entre tais eletrodos, conforme a Figura 5.

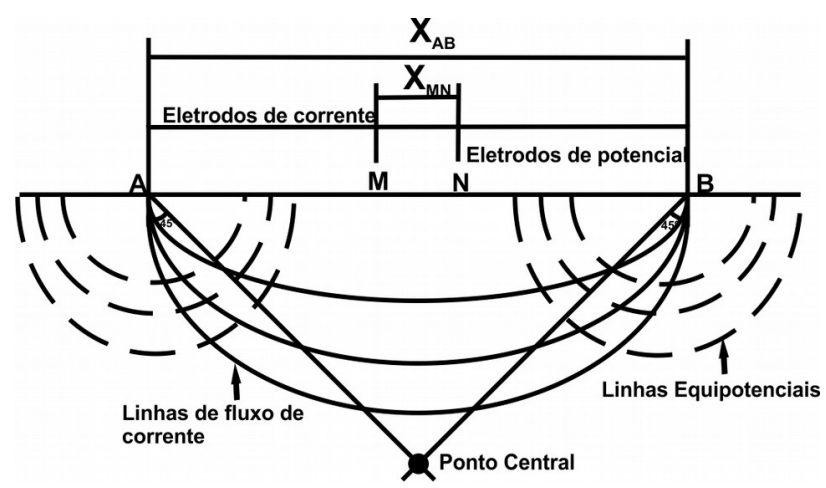

Figura 5 - Indicação dos eletrodos de corrente (AB), de potencial $(\mathrm{MN})$, das linhas de corrente e de equipotencial na técnica da sondagem elétrica vertical (SEV) (modificado de Dentith \& Mudge, 2014).

O método eletromagnético mede a condutividade elétrica aparente $(\sigma a)$ por meio de campos eletromagnéticos induzidos no terreno ( McNeill, 1980). A resposta é expressa em Siemens por metro ( $\mathrm{S} / \mathrm{m})$, ou miliSiemens por metro $(\mathrm{mS} / \mathrm{m})$.

Uma corrente elétrica variável no tempo, emitida por uma bobina transmissora (Tx), gera um campo magnético primário (Hp), que induz correntes elétricas secundárias em um condutor em subsuperfície. Tais correntes secundárias estão associadas a um campo magnético secundário (Hs), que é detectado por uma bobina receptora $(\mathrm{Rx})$, conforme a figura 6 .

A condutividade aparente ( $\sigma a)$ é dada pela equação 4 (McNeill, 1980):

$$
\sigma_{\mathrm{a}}=\frac{4}{\omega \mu_{0} \mathrm{~s}^{2}} \cdot\left(\frac{H s}{H p}\right)
$$

Onde:

$\omega=2 \pi \mathrm{f}$ é a frequência angular;

$\mu 0=$ permeabilidade magnética;

$\mathrm{s}=$ espaçamento entre as bobinas;

Hs = campo magnético secundário;

$\mathrm{Hp}$ = campo magnético primário.

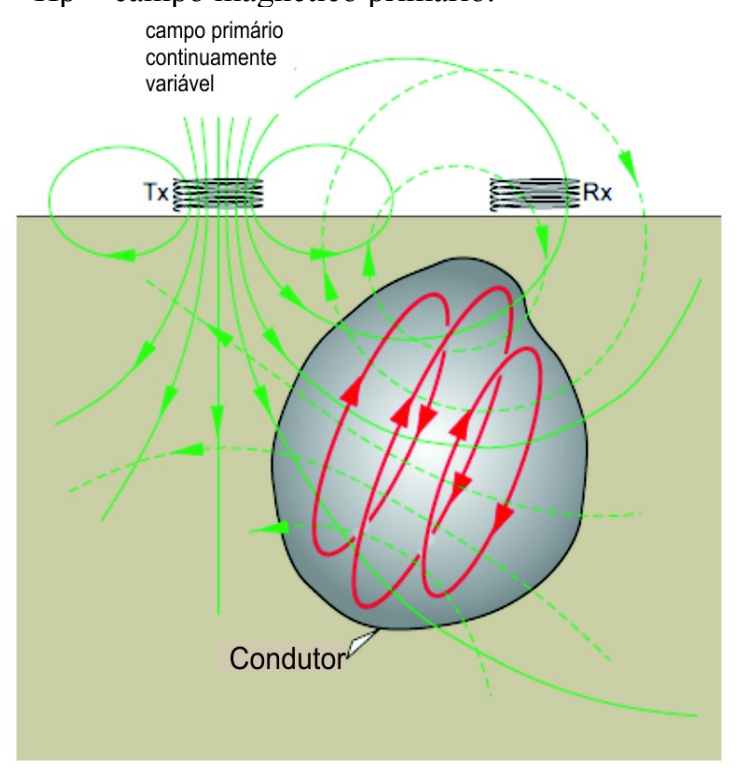

Campo magnético primário

Campo magnético secundário = -

Corrente de Eddy

Figura 6 - Modelo esquemático do método eletromagnético indutivo (modificado de Dentith \& Mudge, 2014). Tx - bobina transmissora, $\mathrm{Rx}$ - bobina receptora. 
A disposição horizontal e coplanar das bobinas Tx e Rx é chamado de arranjo Dipolo Vertical e a disposição das bobinas na vertical e coaxial é denominada arranjo Dipolo Horizontal. A Tabela 1 mostra os espaçamentos entre as bobinas, as frequências de operação do equipamento, e as respectivas profundidades teóricas de exploração (McNeill, 1980).

Tabela 1 - Relação entre os espaçamentos de bobinas, as frequências de operação e as profundidades teóricas de investigações no modo Dipolo Magnético Vertical, para o sistema Geonics EM-34.

\begin{tabular}{ccc}
\hline $\begin{array}{c}\text { Espaçamento entre } \\
\text { as bobinas }(\mathbf{m})\end{array}$ & $\begin{array}{c}\text { Frequência de } \\
\text { operação }(\mathbf{k H z})\end{array}$ & $\begin{array}{c}\text { Profundidade teórica } \\
\text { de investigação } \\
(\mathbf{m})\end{array}$ \\
10 & 6,4 & 15 \\
20 & 1,6 & 30 \\
40 & 0,4 & 60 \\
\hline
\end{tabular}

\section{Aquisição dos Dados Geofísicos}

Para apoiar a pesquisa geofísica, o SETEC-PR solicitou ao Departamento Nacional de Produção Mineral (DNPM) um levantamento de alta resolução espacial da área de estudo por meio de uma tecnologia recente denominada Veículo Aéreo Não Tripulado (VANT). Segundo Bicho et al. (2013), a aplicação do VANT como uma plataforma de sensoriamento remoto possibilita a aquisição de imagens de altíssima resolução espacial e temporal, a um baixo custo de operação e manutenção.

Através do processamento de georreferenciamento e ortorretificação das imagens geradas pelo VANT foi obtida como produto final uma imagem aérea de alta resolução espacial (4 $\mathrm{cm}$ por pixel) de todo o aterro sanitário (Figura 7).

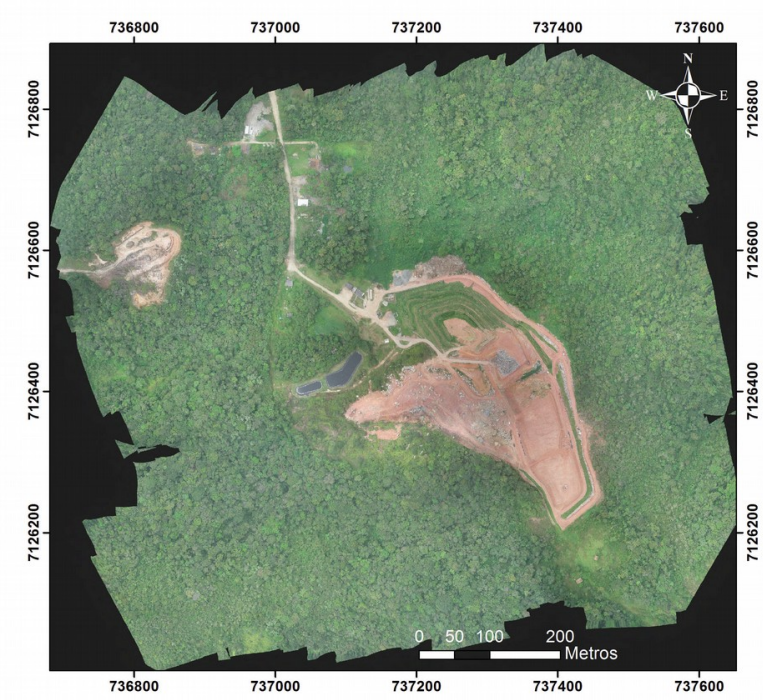

Figura 7 - Imagem aérea obtida pelo VANT (DNPM, 2013).

Os dados dos caminhamentos (CEs), de eletrorresistividade (ER) e polarização induzida (IP) e os da sondagem elétrica vertical (SEV) foram adquiridos por um sistema, fabricado pela Iris Instruments, composto por um transmissor de alta potência (VIP3000W) e um receptor multicanal (ELREC Pro),
A figura 8 mostra a localização das cinco linhas de $\mathrm{ER} / \mathrm{IP}$ (L1=360m; L2=520m; L3=400m; L4=340m e L5=180m) e da SEV. O arranjo dos CEs foi o dipolodipolo $(\mathrm{AM}=\mathrm{MN}=20 \mathrm{~m})$, enquanto o da SEV foi o Schlumberger, com $\mathrm{AB} / 2=150 \mathrm{~m}$. Os dados de IP foram adquiridos no domínio do tempo (2s).

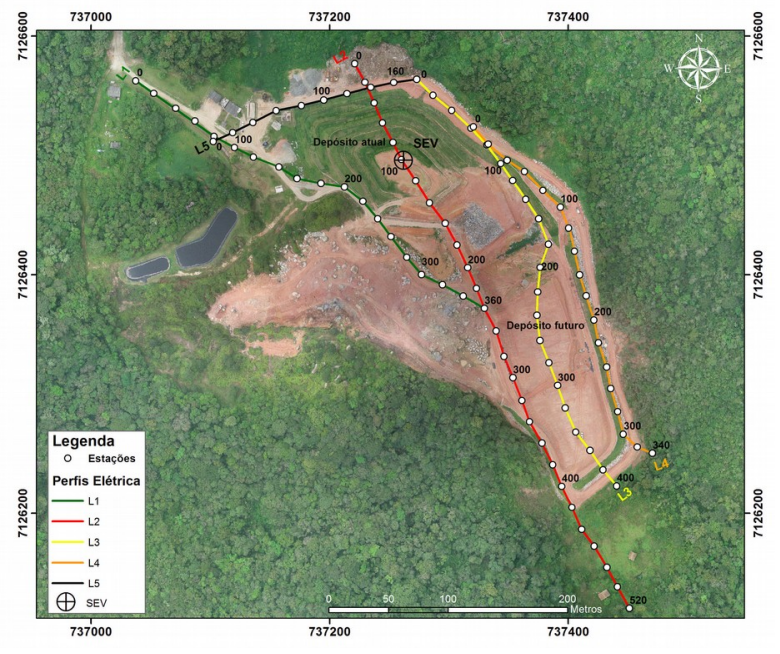

Figura 8 - Mapa de localização dos perfis de eletrorresistividade/polarização induzida (CE) e da sondagem elétrica vertical (SEV).

$\mathrm{O}$ equipamento utilizado na aquisição dos dados eletromagnéticos foi o EM34-3, fabricado pela Geonics. É composto por duas bobinas, uma transmissora e outra receptora, além de dois módulos, um de controle e outro de leitura.

O levantamento EM foi executado no modo dipolo vertical, com bobinas espaçadas de $20 \mathrm{~m}$, intervalo de amostragem de $10 \mathrm{~m}$, ao longo de cinco perfis (EM34$3 \mathrm{~A}=1070 \mathrm{~m} ; \mathrm{EM} 34-3 \mathrm{~B}=70 \mathrm{~m} ; \mathrm{EM} 34-3 \mathrm{C}=110 \mathrm{~m}$; EM34-3D $=80 \mathrm{~m}$ e EM34-3E $=130 \mathrm{~m})$. O perfil $(E M 34-3 F=130 m)$ foi conduzido com espaçamento entre bobinas de $40 \mathrm{~m}$ e intervalo de amostragem de 10m (Figura 9).

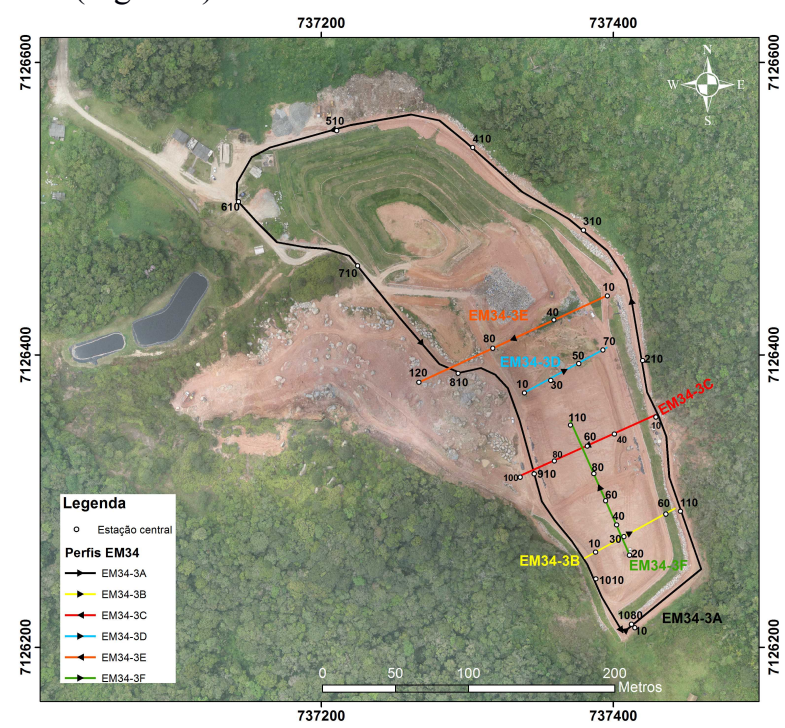

Figura 9 - Mapa de localização dos perfis eletromagnéticos realizados com o EM34-3.

Os software utilizados para o processamentos dos dados de ER e IP foram o Oasis MontajTM e o Zonge 2D Inversion for InteractiveTM IP, ambos da 
Geosoft/Interpex. Os resultados dos modelos de profundidade da resistividade e da polarização induzida, obtidos por inversão, foram posteriormente correlacionados com os dados de condutividade aparente adquiridos pelo EM34-3.

\section{Resultados}

\subsection{Métodos de Eletrorresistividade e Polarização Induzida}

Os modelos 2D de profundidade, obtidos por inversão, permitiram delinear o background e as áreas possivelmente afetadas pelo contaminante, enquanto a SEV possibilitou estimar a espessura do depósito.
No modelo da resistividade da Linha L1 (figura 10, painel superior), as baixas resistividades ( $<50$ Ohm.m) foram associadas ao percolado/chorume, o que ficou bem evidenciado entre as estações $180 \mathrm{~m}$ e $280 \mathrm{~m}$. Altos valores de resistividade foram associados aos granitos (figura 10). No painel inferior, baixos valores de cargabilidade só em parte coincidem com índices baixos de resistividade, refletindo o chorume condutivo e não polarizável. Contudo, entre as estações $180 \mathrm{~m} \mathrm{e}$ $240 \mathrm{~m}$, nota-se a correspondência entre baixos valores de resistividade e elevados de cargabilidade, o que pode ser explicado por material polarizável (resíduos metálicos) observado in loco.

\section{Linha 1}

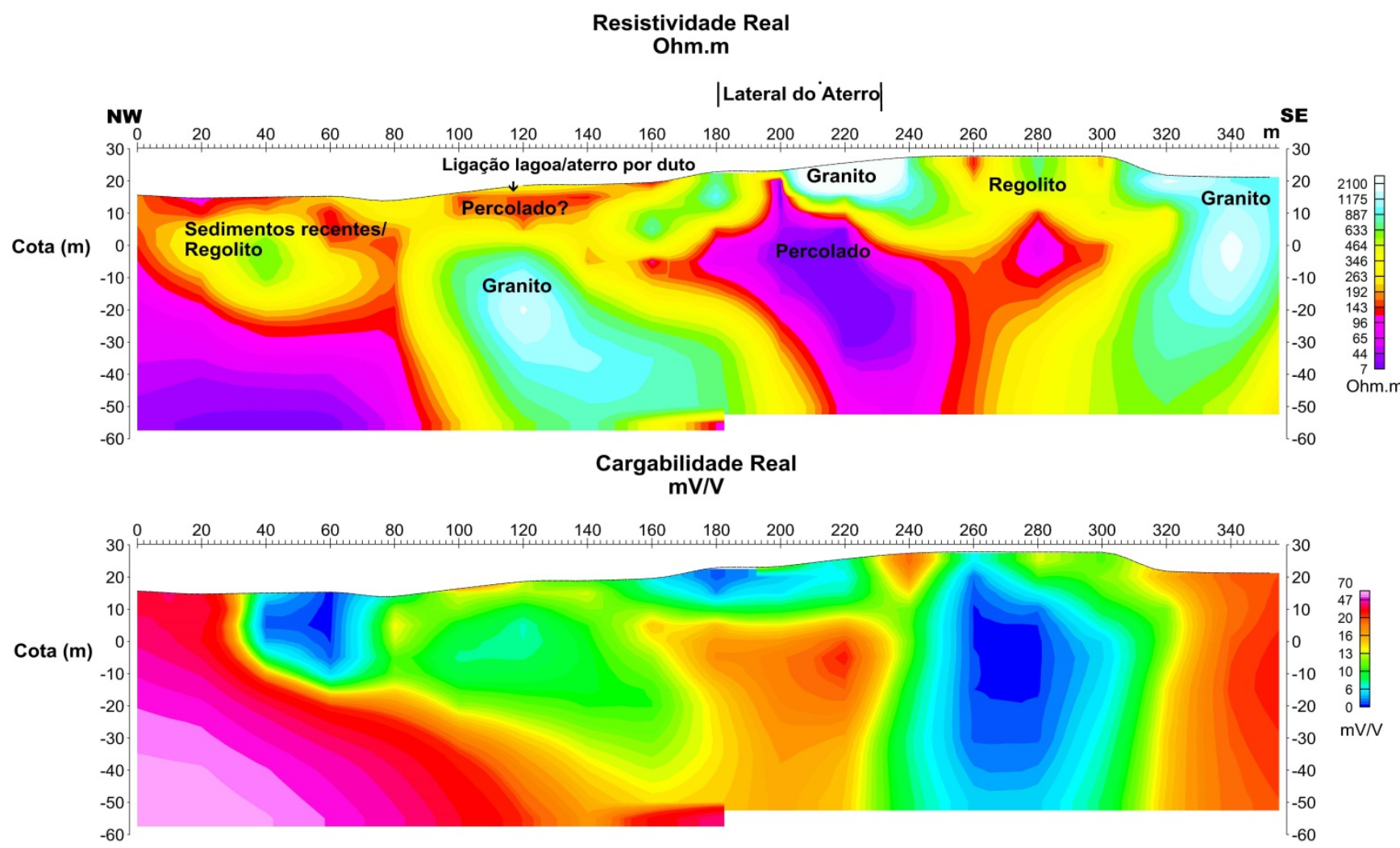

Figura 10 - Modelo de profundidade da resistividade (painel superior) e da cargabilidade (painel inferior) da Linha L1 (vide localização na Figura 8).

Nos painéis superiores dos modelos das Linhas L2 (Figura 11) e L3 (Figura 12), fica evidente o contraste de resistividade entre o depósito atual (baixas resistividades, < 50 Ohm.m) e o futuro (altas resistividades, $>900$ Ohm.m), estas últimas associadas ao embasamento, material de empréstimo e/ou geomembrana. Observa-se que o depósito atual pode ser delineado tanto lateral quanto verticalmente, entre as estações $0 \mathrm{~m}$ e $220 \mathrm{~m}$. Conforme já citado, só em parte as baixas cargabilidades coincidem com as baixas resistividades, características geofísicas do percolado. Entretanto, as altas cargabilidades em superfície nos painéis inferiores das figuras 10 e 11 , refletem as coberturas areno-argilosas. 


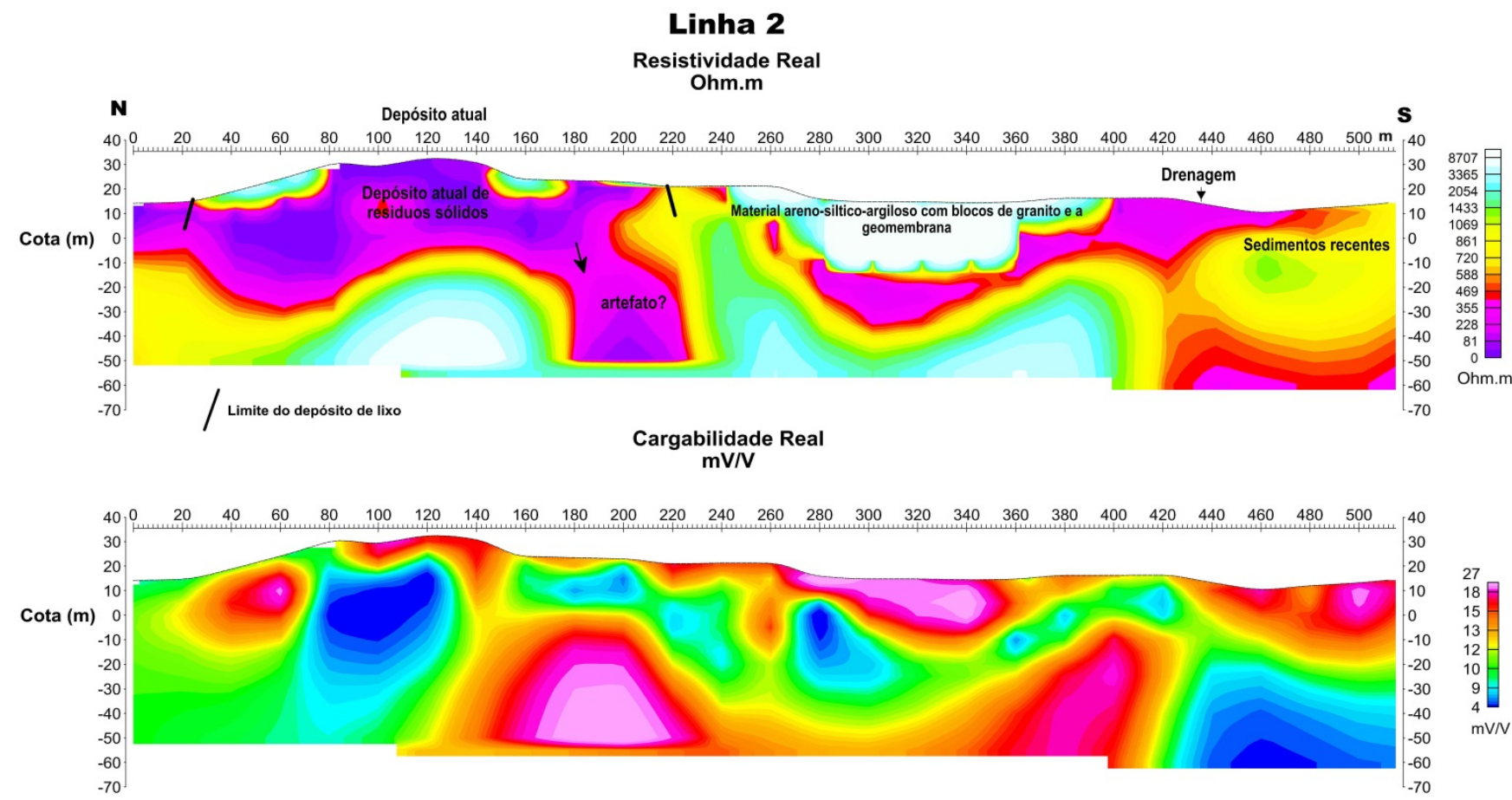

Figura 11 - Modelo de profundidade da resistividade (painel superior) e da cargabilidade (painel inferior) da Linha L2 (vide localização na Figura 8).

No painel superior da Figura 13 (Linha L4), se observa entre as estações $0 \mathrm{~m}$ e $140 \mathrm{~m}$, uma expressiva camada condutiva $(<50$ Ohm.m), relacionada ao percolado. Dois outros níveis subordinados são registrados entre as estações $150 \mathrm{~m}$ e $220 \mathrm{~m}$ e $220 \mathrm{~m}$ e $320 \mathrm{~m}$. Valores intermediários e elevados foram associados, respectivamente, aos sedimentos e aos granitos. Praticamente todos os níveis superficiais de baixa resistividade estão vinculados a baixas cargabilidades, caracterizando a assinatura geofísica do contaminante.

$\mathrm{Na}$ Linha L5, os valores de baixa resistividades $(<50$ Ohm.m) que estão localizados entre a estação $60 \mathrm{~m}$ e a extremidade oriental do modelo são bem delineadas, tanto lateralmente quanto em profundidade e foram associadas ao percolado. Já entre as estações 0 e 60 m, os valores intermediários e elevados foram associados, respectivamente, aos sedimentos ou terraplanagem e aos granitos. Quanto ao painel inferior da mesma figura, observa-se uma forte anomalia de cargabilidade a qual não se sabe ao certo a sua origem, este parâmetro encontra-se entre as estações 60 e $80 \mathrm{~m}$ (Figura 14).

A interpretação da SEV (Figura 15) resultou em três camadas: a primeira, com $1,5 \mathrm{~m}$ de espessura e resistividade de $35,5 \mathrm{Ohm} . \mathrm{m}$ foi associada a cobertura areno-síltico-argilosa; a segunda, com $30 \mathrm{~m}$ de espessura e resistividade de 16,4 Ohm.m, representou os resíduos em conjunto com o chorume do depósito; e a terceira, com resistividade muito elevada (3243 Ohm.m) foi interpretada como resposta do embasamento granítico e/ou geomembrana. 

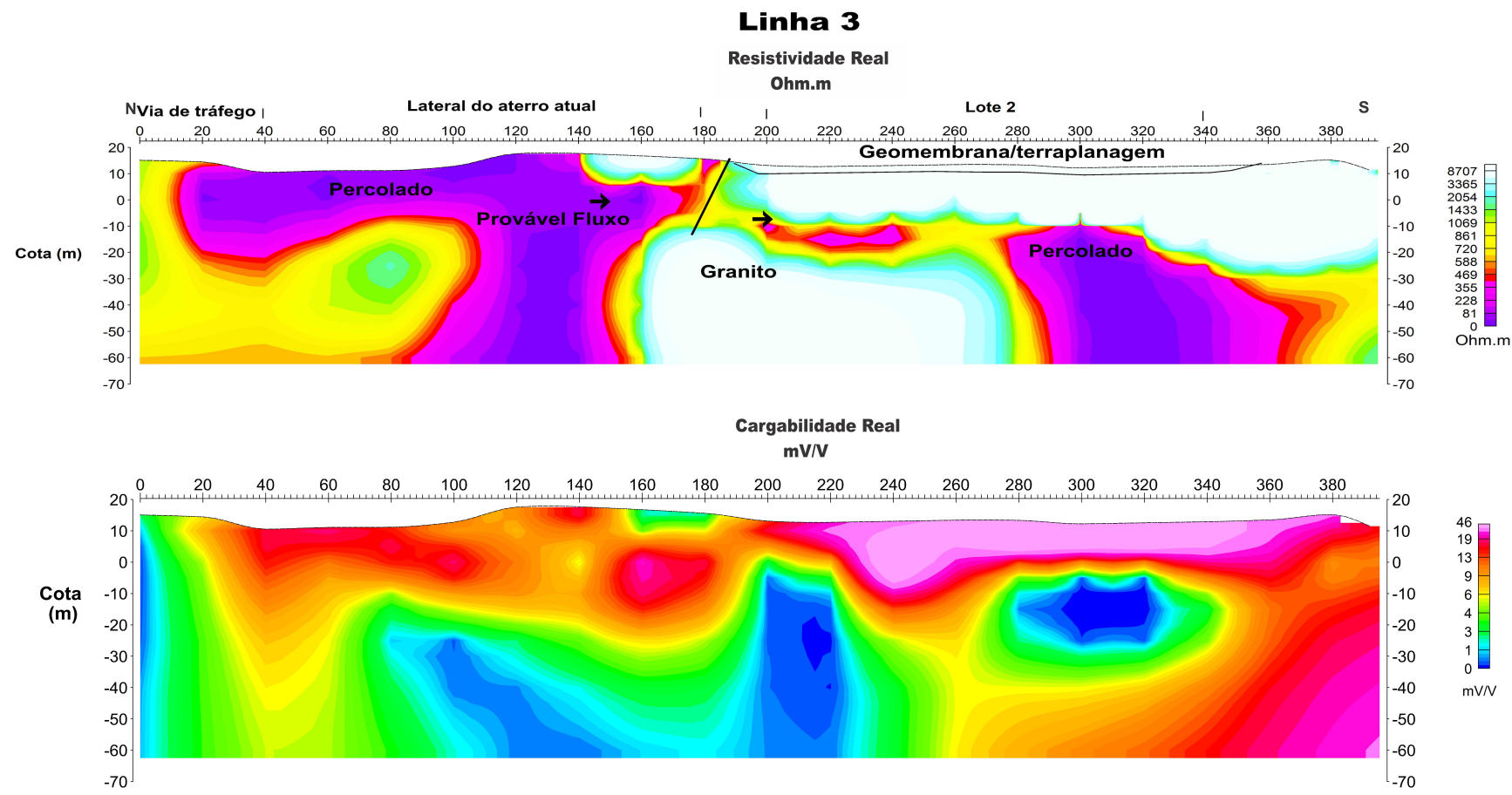

Figura 12 - Modelo de profundidade da resistividade (painel superior) e da cargabilidade (painel inferior) da Linha 3 (vide localização na Figura 8).

\section{Linha 4}
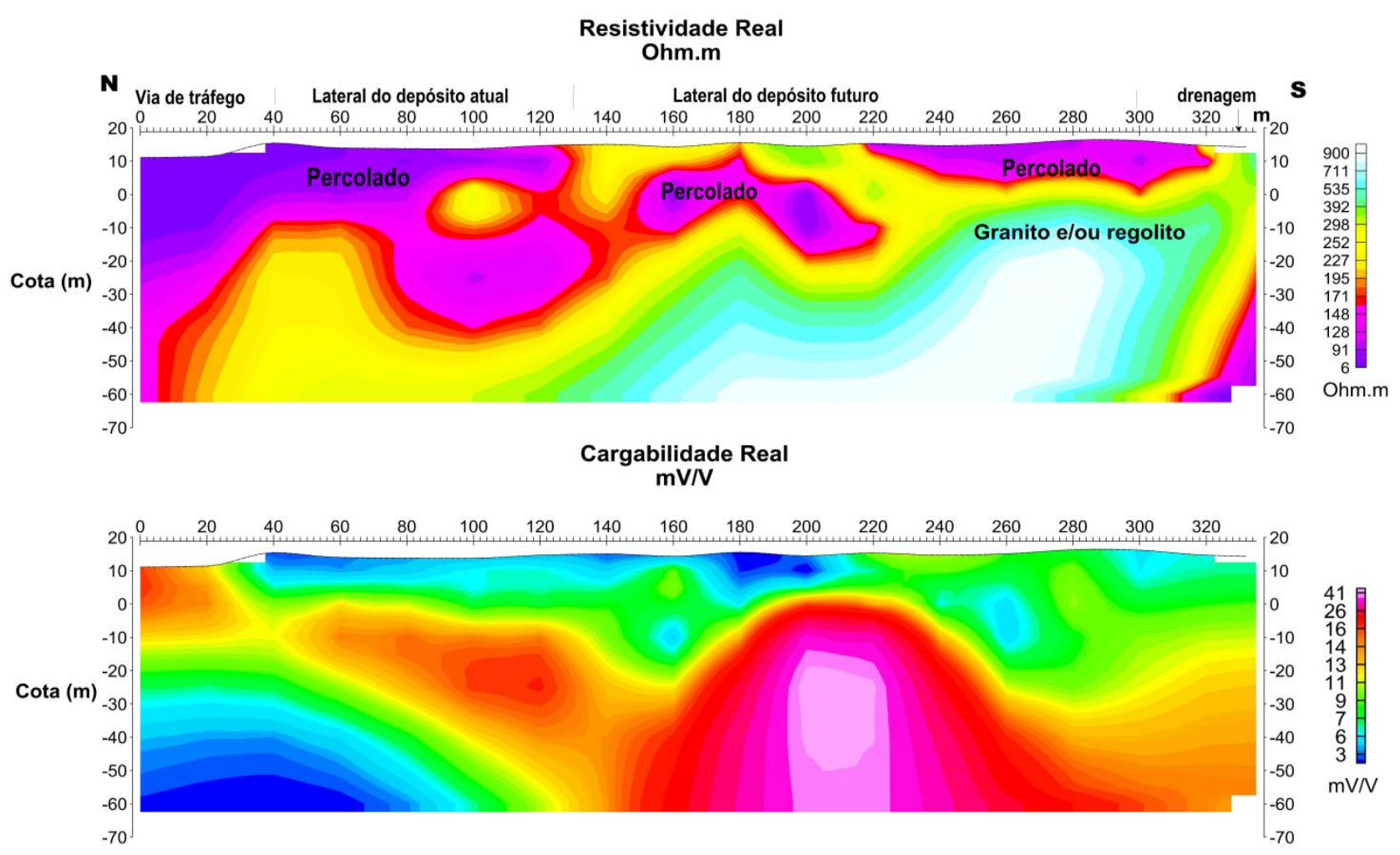

Figura 13 - Modelo de profundidade da resistividade (painel superior) e da cargabilidade (painel inferior) da Linha L4 (vide localização na Figura 8). 


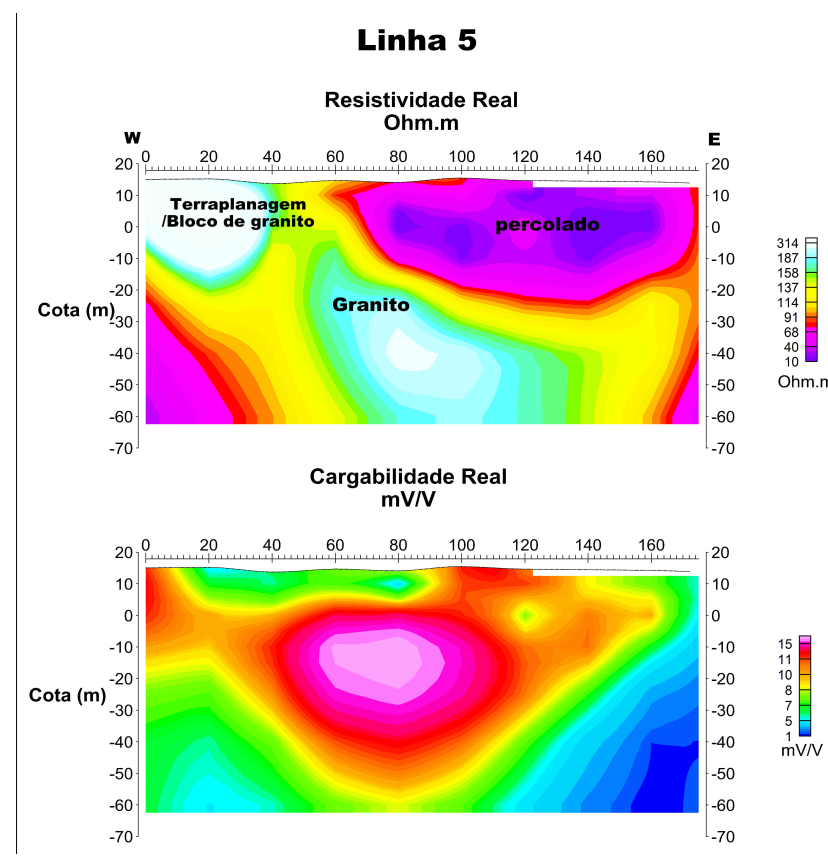

Figura 14 - Modelo de profundidade da resistividade (painel superior) e da cargabilidade (painel inferior) da Linha 5 (vide localização Figura 8).

SEV1

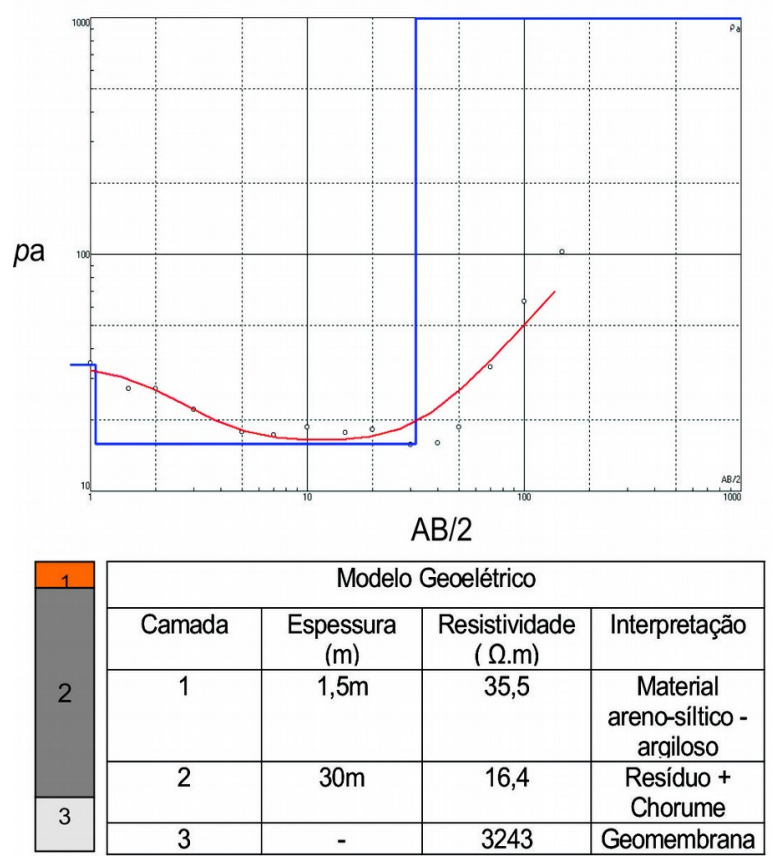

Figura 15 - A) Curva de resistividade aparente com o modelo ajustado e B) Modelo geoelétrico elaborado a partir da SEV1 (vide localização na Figura 8).

\subsection{Método Eletromagnético}

O perfil EM34-3A (vide figura 9), circunscreveu todo o depósito, cujos resultados são apresentados na figura 16. Observa-se nesta figura dois padrões distintos de condutividade aparente ( $\sigma \mathrm{a})$ : as extremidades são marcadas por valores baixos a intermediários de $\sigma a(8-26 \mathrm{mS} / \mathrm{m})$, indicando materiais geológicos, e outro na porção central, com altas condutividades $(26-62 \mathrm{mS} / \mathrm{m})$, associado ao percolado.

A figura 17 exibe os perfis EM34-3B, EM34-3C e EM34-3D que foram adquiridos sobre o futuro depósito com espaçamento entre as bobinas de $20 \mathrm{~m}$ (vide figura 9). Baixos valores de condutividade $(<14$ $\mathrm{mS} / \mathrm{m}$ ) foram associados ao sedimentos e granitos na área.

O perfil EM34-3E (Figura 18), foi realizado sobre o depósito atual. As altas condutividades aparentes ( $>23$ $\mathrm{mS} / \mathrm{m}$ ) foram associadas ao percolado, enquanto que as baixas condutividades $(<14 \mathrm{mS} / \mathrm{m})$, observadas na porção oeste do perfil, caracterizam o embasamento granítico.

O perfil EM-34-3F (Figura 19) foi levantado sobre o depósito futuro, com um espaçamento entre as bobinas de $40 \mathrm{~m}$. Os resultados também mostram altas condutividades aparentes $(>23 \mathrm{mS} / \mathrm{m})$, que foram associadas ao percolado.

Observa-se nos perfis EM34-3B, EM34-3C e EM343D (Figura 17) e no perfil EM34-3F (Figura 19) adquiridos sobre o depósito futuro diferentes valores de condutividade aparente. Esta variação é decorrente da profundidade de investigação, a qual está relacionada com o espaçamento entre as bobinas. Desta forma, os valores de condutividade aparente $(>23 \mathrm{mS} / \mathrm{m})$ obtidos no perfil EM34-3F foram associados ao percolado, ou seja, sugerem que esta área em uma maior profundidade de investigação possa estar contaminada. 


\section{EM34-3A}

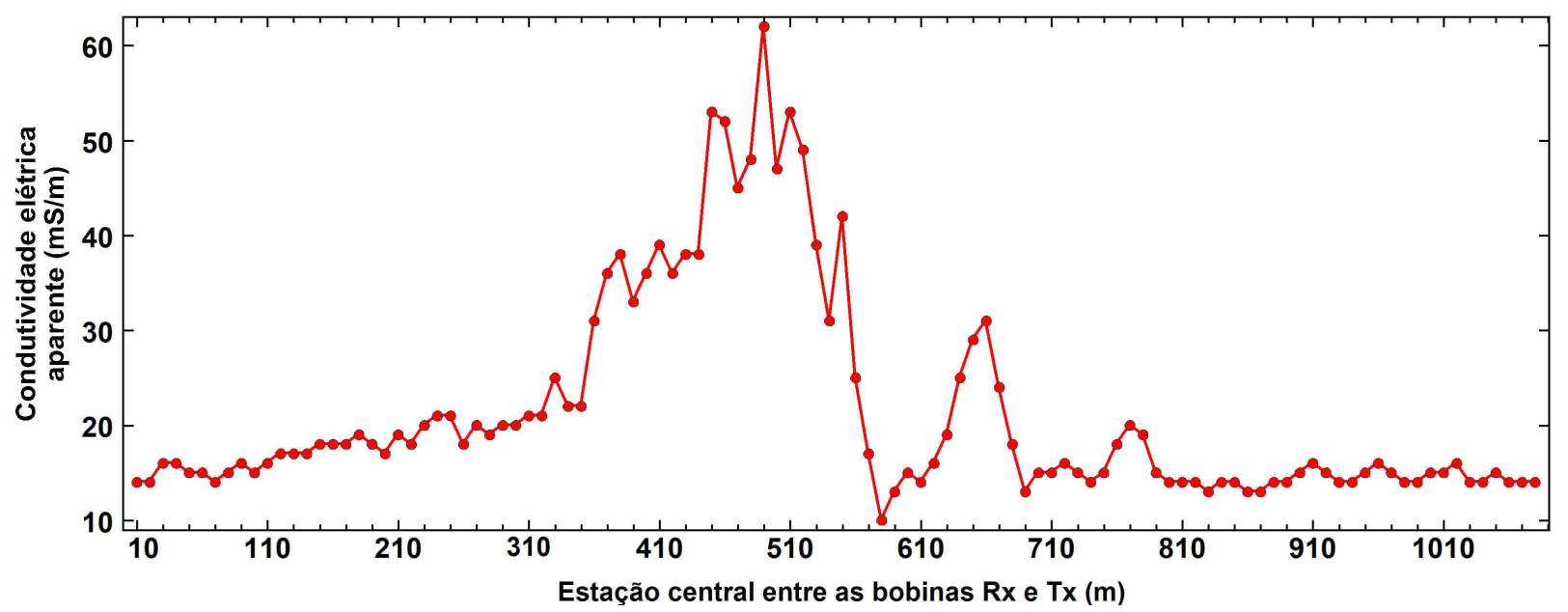

Figura 16 - Perfil EM34-3A realizado no entorno do depósito (vide localização na Figura 9).

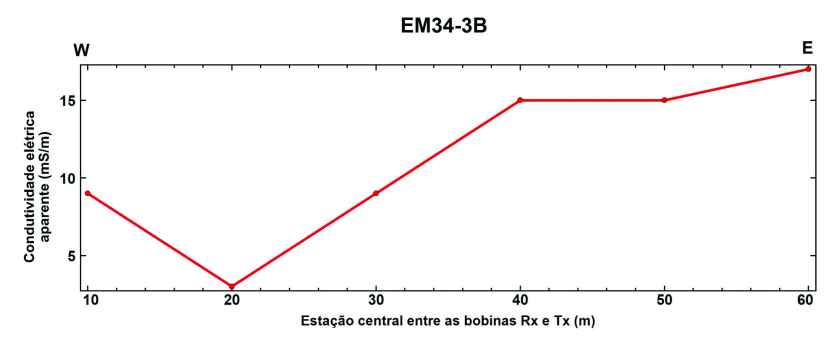

EM34-3C
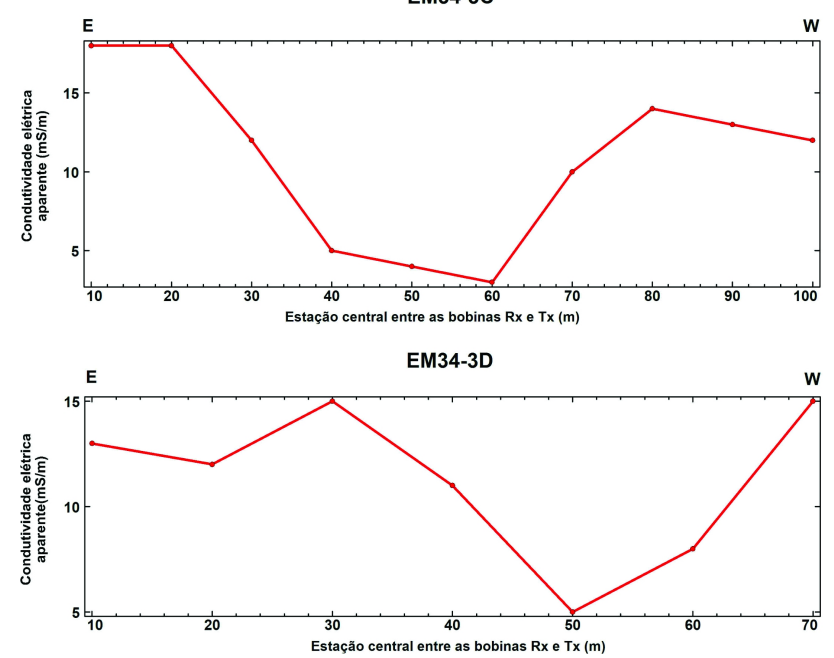

Figura 17 - Resultados dos perfis EM34-3B, EM34-3C e EM343D obtidos sobre o depósito futuro (vide localização na Figura 9).

\subsection{Correlação dos Resultados de Eletrorresistividade e Eletromagnéticos}

Com a finalidade de comparar os dados obtidos pelos métodos da eletrorresistividade (ER) e eletromagnético (EM34-3), o perfil EM34-3A foi dividido em três segmentos (EM34-3A1, EM34-3A2, EM34-3A3). A correlação espacial entre os perfis de ER e EM34-3 podem ser observados na Figura 20 e na Tabela 2.

No perfil de correlação PC1 (Figura 21), observa-se que no painel inferior os baixos valores de resistividade (< 50 Ohm.m) correspondem a elevados valores de condutividade aparente $(>20 \mathrm{mS} / \mathrm{m})$, no painel superior, caracterizando a assinatura geofísica do percolado.

No perfil de correlação PC2 (Figura 22), resistividades menores que $50 \mathrm{Ohm} . \mathrm{m}$ (painel inferior) e de condutividade aparente entre 25 e $60 \mathrm{mS} / \mathrm{m}$ (painel superior), também são indicativos da pluma de contaminação.

No perfil de correlação PC3 (Figura 23), os valores de resistividade menores que 50 Ohm.m (painel inferior), se relacionam a valores de condutividade aparente entre 25 e $30 \mathrm{mS} / \mathrm{m}$ (painel inferior), igualmente refletindo o percolado. Todavia, não se verifica uma perfeita correlação espacial, talvez em função do perfil eletromagnético se localizar mais afastado do depósito. 


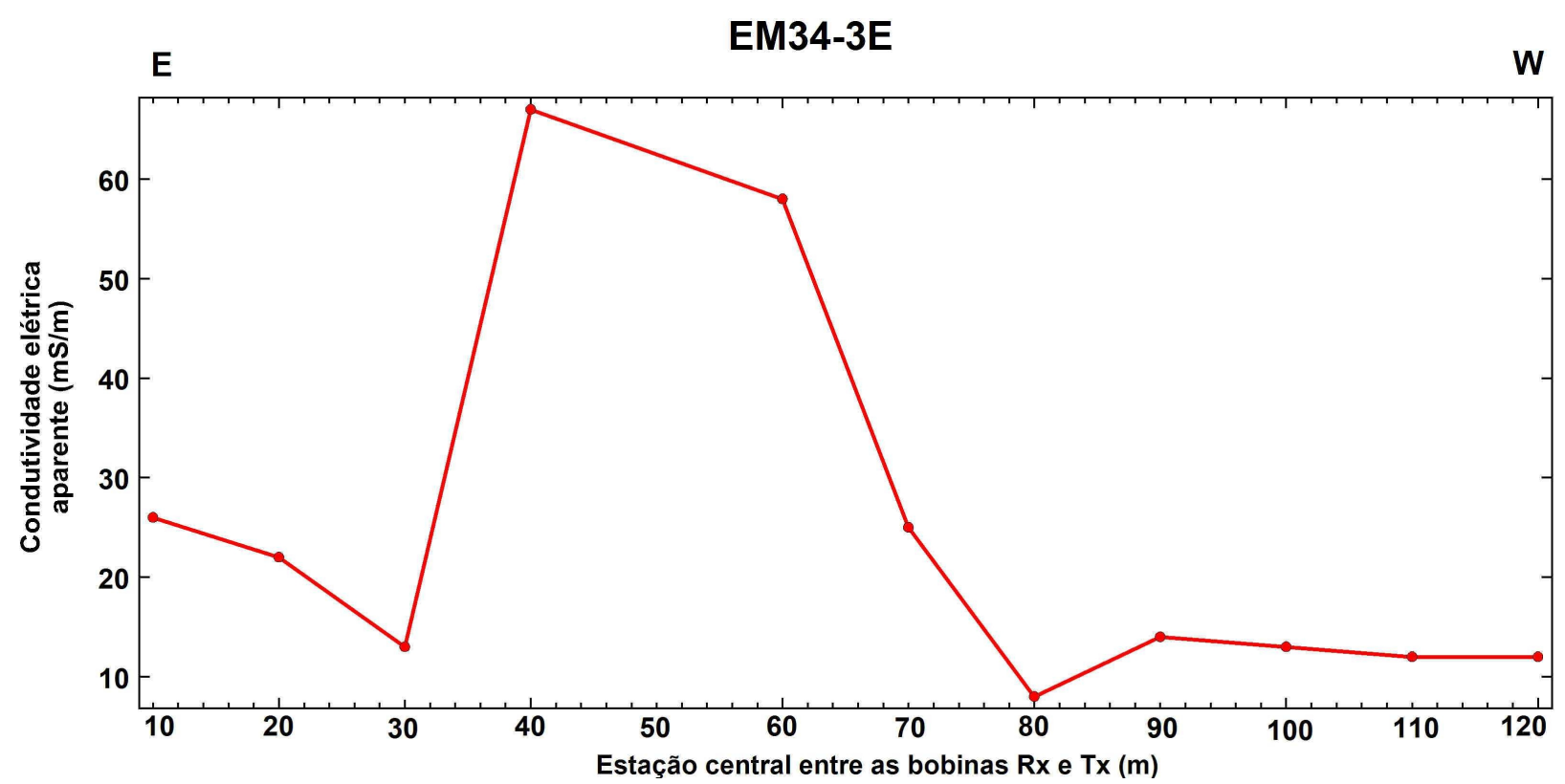

Figura 18 - Perfil EM34-3E realizado no depósito atual (vide localização na Figura 9).

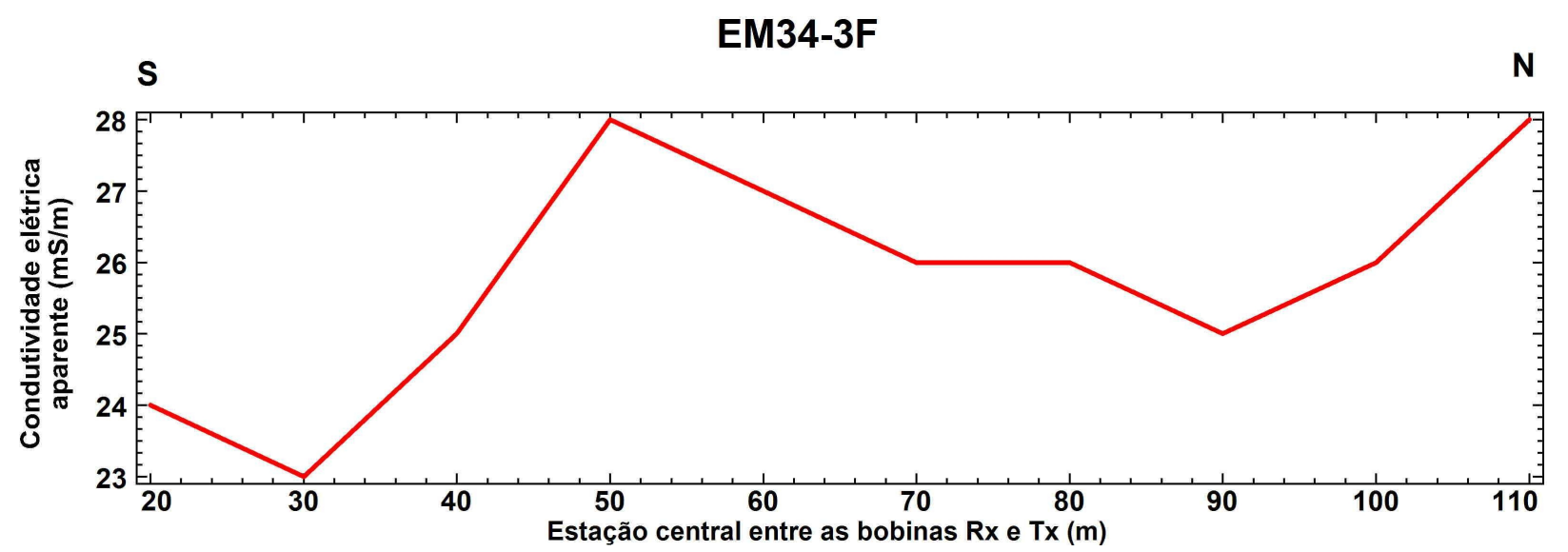

Figura 19 - Perfil EM34-3F realizado no depósito futuro (vide localização na Figura 9).

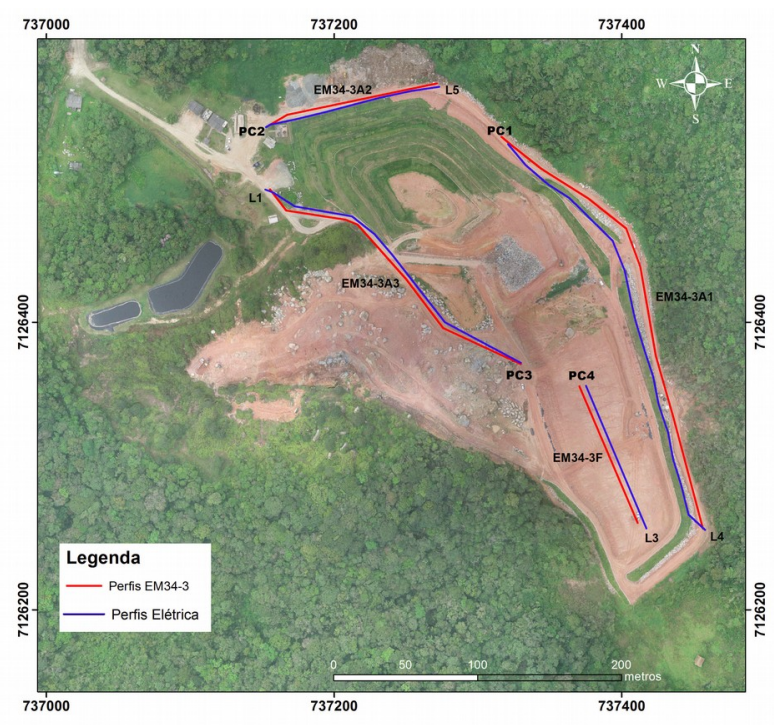

Figura 20 - Correlação espacial entre os perfis elétricos e eletromagnéticos (EM34-3).

Tabela 2 - Perfis de correlação eletromagnéticos (EM34-3) e elétricos (modelos de resistividade) e suas extensões.

\begin{tabular}{cccc}
\hline $\begin{array}{c}\text { Perfis de } \\
\text { correlação }\end{array}$ & $\begin{array}{c}\text { Eletro- } \\
\text { magnéticos }\end{array}$ & Elétricos & Extensão (m) \\
\hline PC1 & EM34-3A1 & Linha 4 & 320 \\
\hline PC2 & EM34-3A2 & Linha 5 & 120 \\
\hline PC3 & EM34-3A3 & Linha 1 & 220 \\
\hline PC4 & EM34-3F & Linha 3 & 110 \\
\hline
\end{tabular}

No perfil de correlação PC4 (Figura 24), resistividades menores que $50 \mathrm{Ohm} . \mathrm{m}$ (painel inferior) se relacionam com valores de condutividade aparente entre 23 e $28 \mathrm{mS} / \mathrm{m}$ (painel superior), também associados ao percolado. 


\section{Perfil Correlação 1}

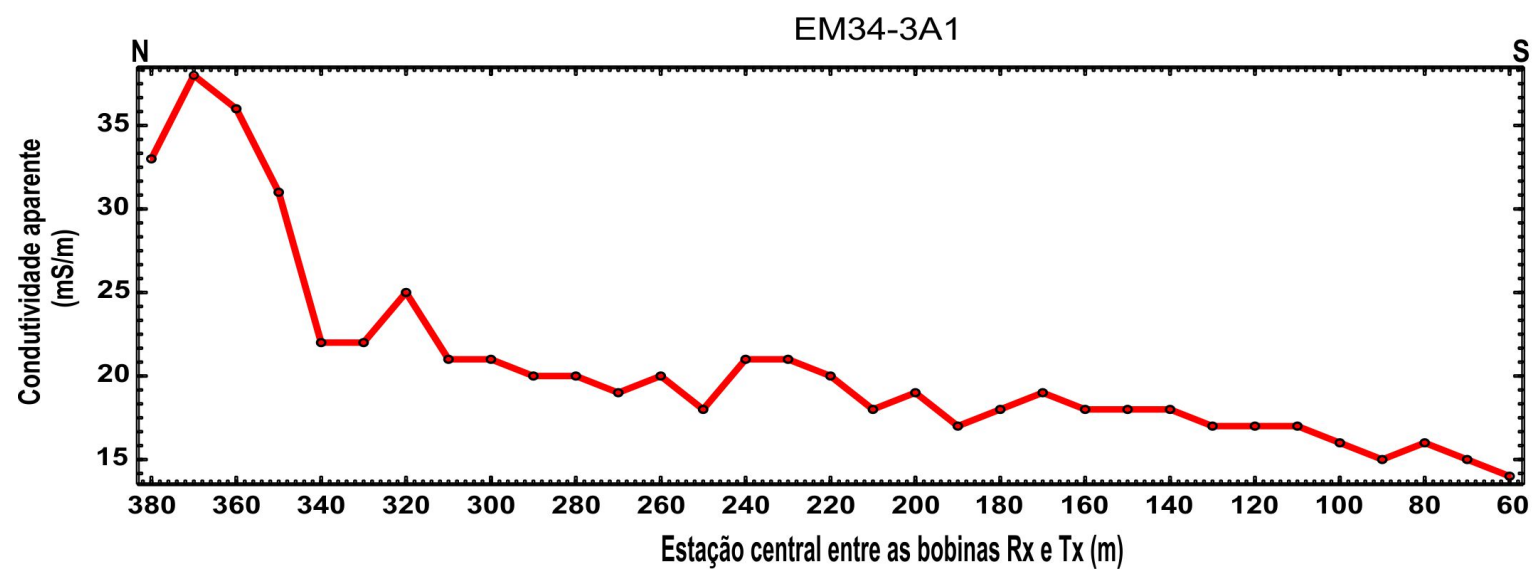

\section{Linha 4}

Resistividade Real

Ohm.m

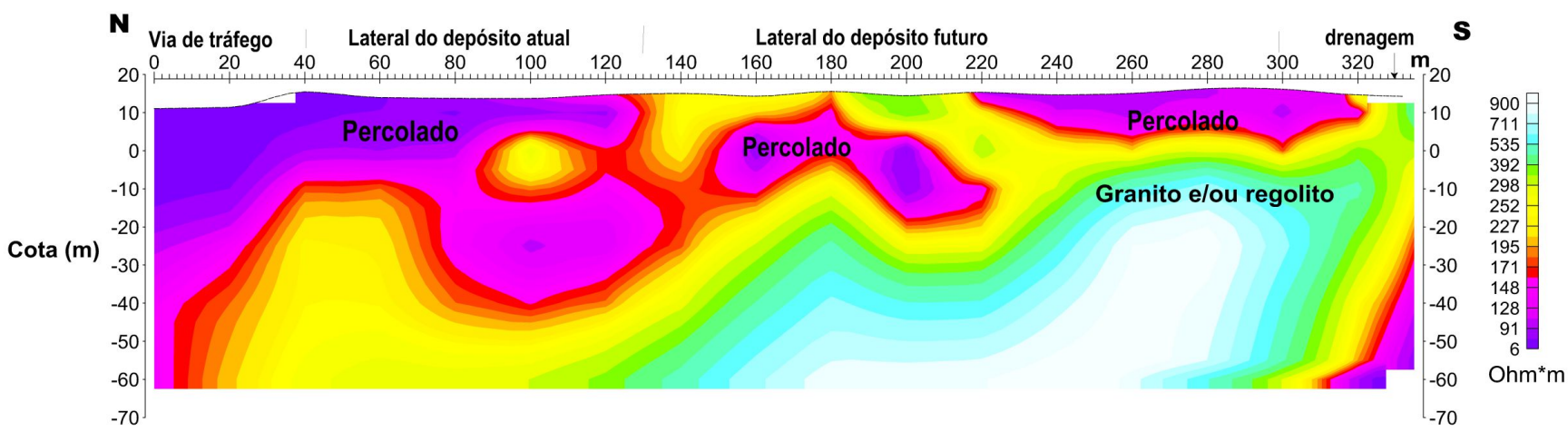

Figura 21 - Perfil de correlação PC1 indicando o modelo de resistividade (painel inferior) e os dados de condutividade aparente (painel superior). 


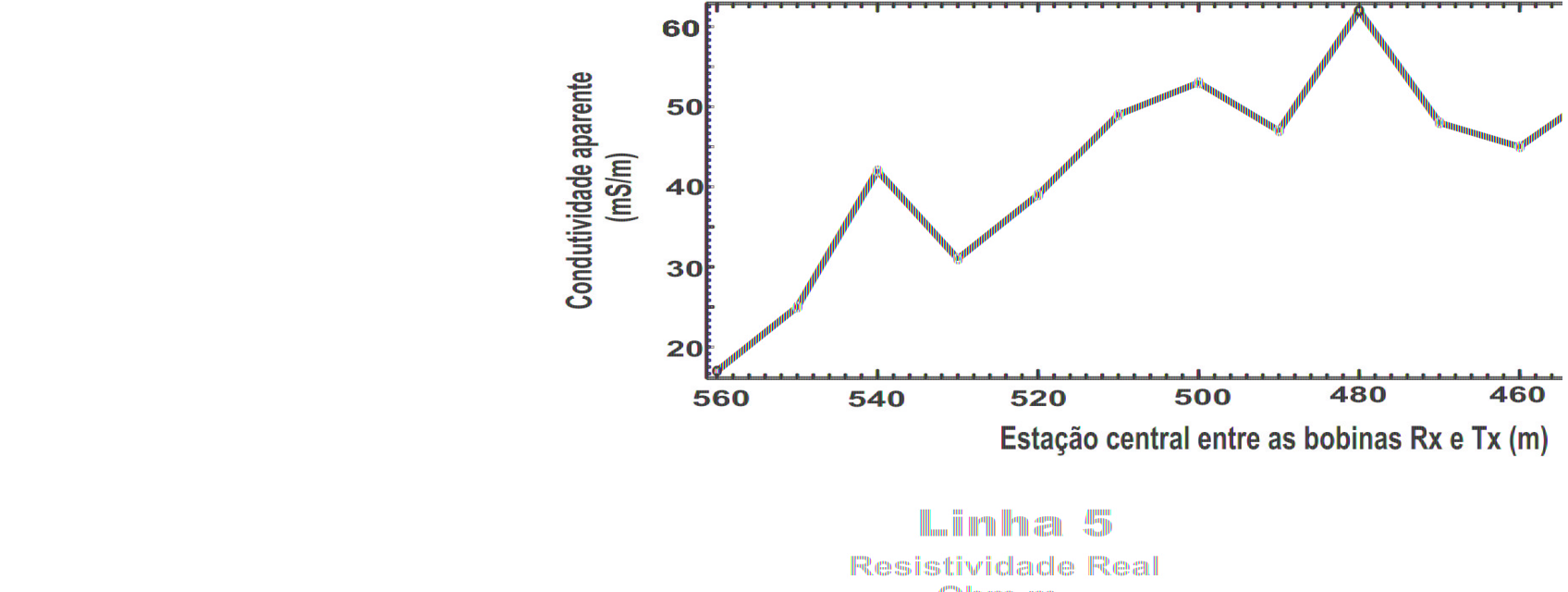

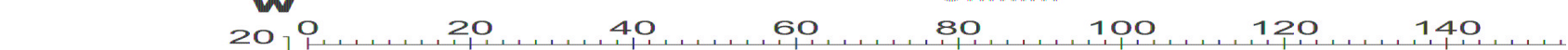

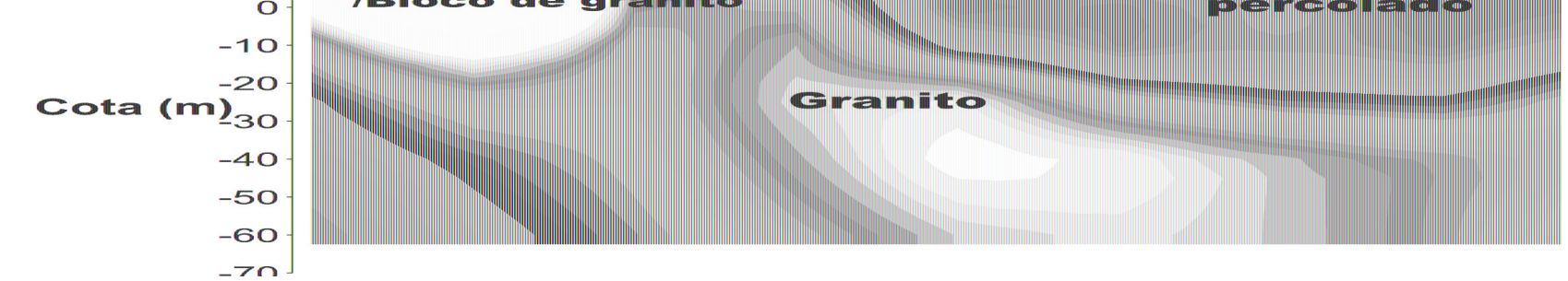

Figura 22 - Perfil de correlação PC2 indicando o modelo de resistividade (painel inferior) e os dados de condutividade aparente (painel superior). 


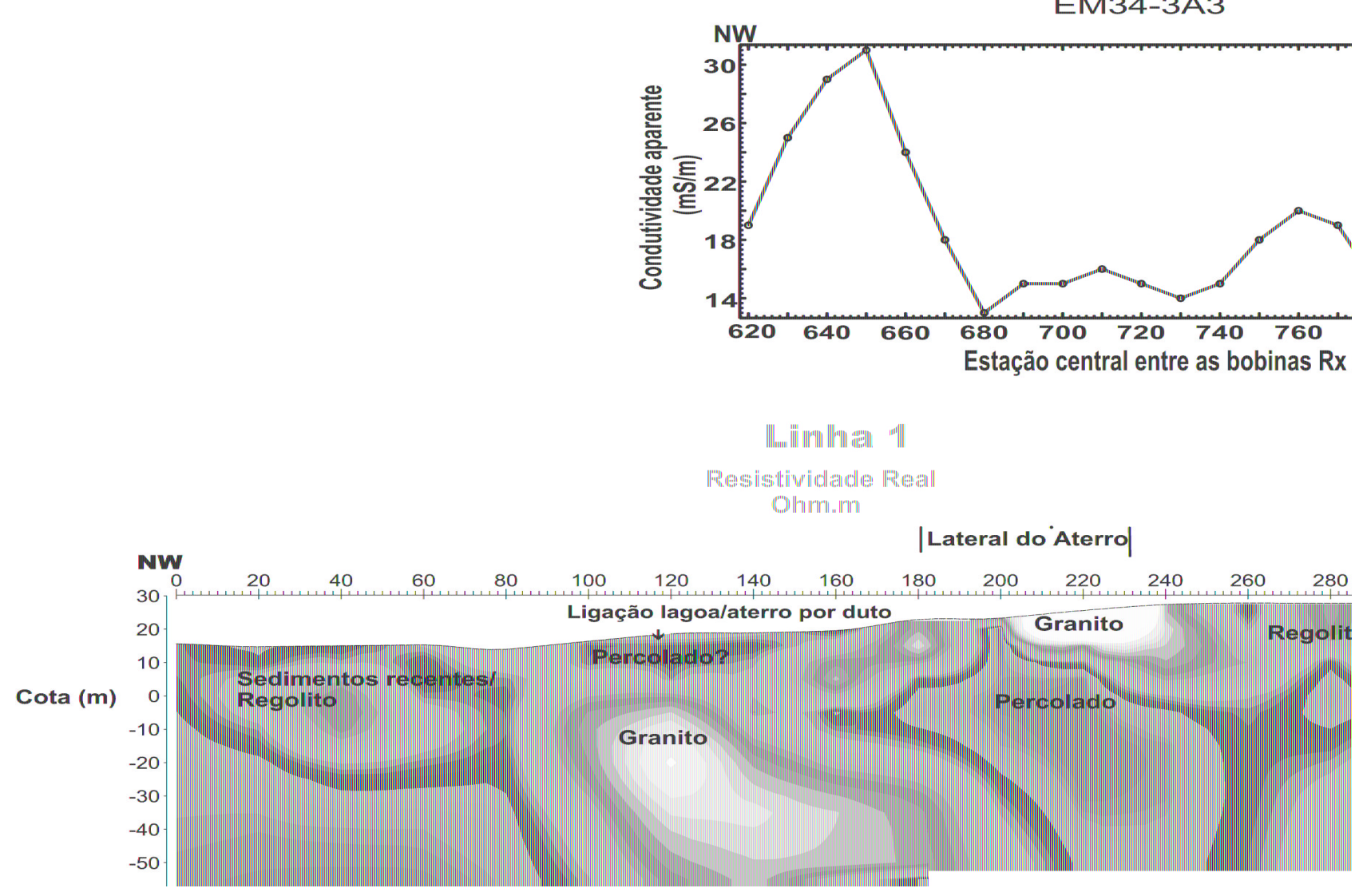

Figura 23 - Perfil de correlação PC1 indicando o modelo de resistividade (painel inferior) e os dados de condutividade aparente (painel superior).

\section{Perfil Correlação 4}

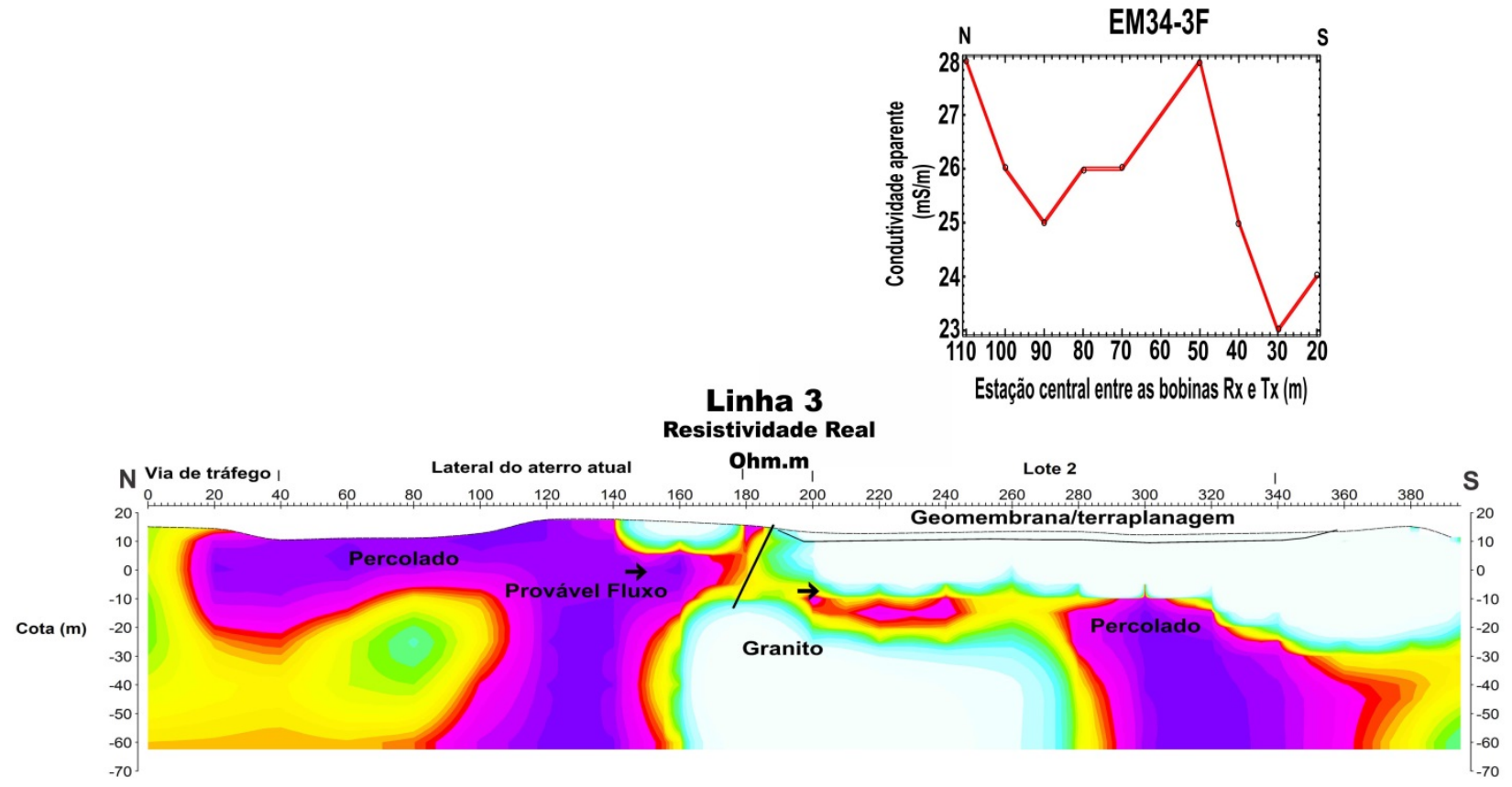

Figura 24 - Perfil de correlação PC4 indicando o modelo de resistividade (painel inferior) e os dados de condutividade aparente (painel superior).

Relacionando-se os dados de eletrorresistividade e eletromagnéticos foi possível separar os seguintes 
tratos: (i) áreas possivelmente contaminadas; (ii) áreas suspeitas de contaminação e (iii) áreas não contaminadas, as quais são ilustradas pela Figura 25, bem como identificar seus respectivos parâmetros geoelétricos, conforme a Tabela 3 .

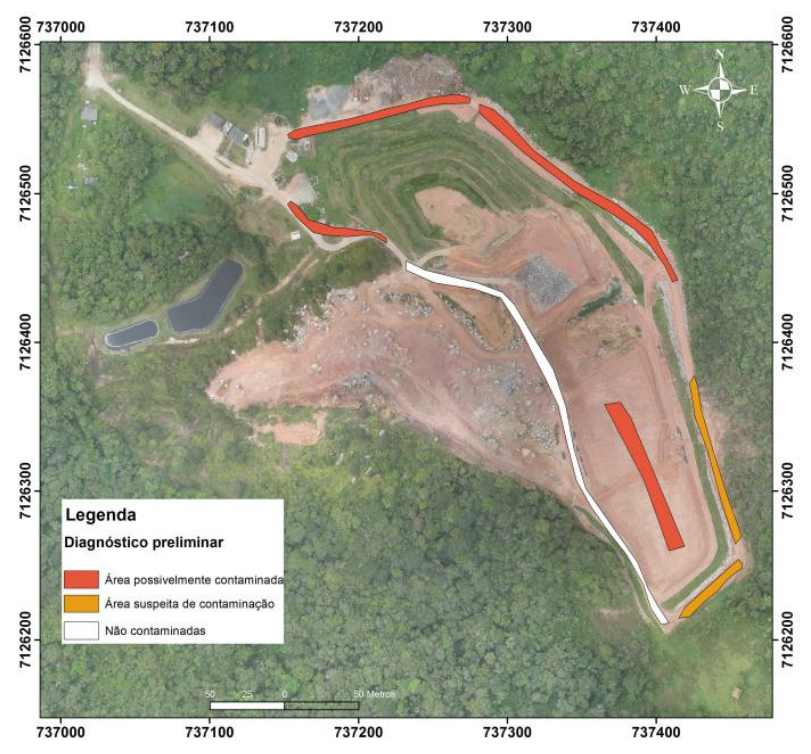

Figura 25 - Mapa sugestivo das áreas possivelmente contaminadas, suspeitas de contaminação e não contaminadas por pluma de contaminação.

Tabela 3 - Parâmetros geoelétricos característicos de áreas contaminadas, suspeitas de contaminação e não contaminadas.

\begin{tabular}{|c|c|c|}
\hline Áreas & $\begin{array}{l}\text { Resistividade } \\
\text { (Ohm.m) }\end{array}$ & $\begin{array}{c}\text { Condutividade } \\
(\mathrm{mS} / \mathrm{m})\end{array}$ \\
\hline $\begin{array}{l}\text { Possivelmente } \\
\text { Contaminadas }\end{array}$ & $<50$ & $>20$ \\
\hline $\begin{array}{ll}\text { Suspeitas } & \text { de } \\
\text { contaminação } & \end{array}$ & $50-70$ & 15 a 20 \\
\hline Não contaminadas & $>70$ & $<15$ \\
\hline
\end{tabular}

\section{Conclusões}

O desempenho dos métodos da eletrorresistividade e eletromagnético foram considerados satisfatórios na delimitação da pluma de contaminação no depósito atual. Ficou evidenciado com clareza o contraste entre os tratos condutivos associados ao depósito atual e os resistivos vinculados ao depósito futuro. Os modelos L3 de resistividade e EM34-3F de condutividade sugerem a presença de um percolado abaixo da geomembrana que pode ter origem relacionada ao antigo lixão ou ao depósito atual. Entretanto, os resultados do método de polarização induzida não foram satisfatórios, evidenciando sua maior sensibilidade aos resíduos metálicos. Outro resultado importante foi a integração dos dados de eletrorresistividade e eletromagnéticos, a qual permitiu sugerir tratos possivelmente contaminadas $(<50$ Ohm.m; > $20 \mathrm{mS} / \mathrm{m}$ ), suspeitos de contaminação (5070 Ohm.m; $15-20 \mathrm{mS} / \mathrm{m})$ e não contaminadas (>70 Ohm.m; <15 mS/m).

\section{Agradecimentos}

Os autores agradecem ao geólogo perito criminal federal Dr. Fábio Augusto da Silva Salvador (DPF-PR) e a geóloga coordenadora do projeto VANT Dra. Cristina Bicho (DNPM-DF), pelo auxílio na pesquisa. Ao Laboratório de Pesquisa em Geofísica Aplicada (LPGA-UFPR) pelo apoio financeiro e ao Serviço Geológico do Brasil (CPRM) pela cessão do equipamento geofísico EM34-3. Ao colega geólogo MSc. André Luis Spisila (UFPR) e ao técnico Joelson Wambier Fialla (UFPR) pela ajuda na aquisição dos métodos geofísicos.

\section{Referências bibliográficas}

BICHO C. P., SILVA L.S., MEDEIROS C.W., SILVA C.A., KUTCHENSKI F.E.J., GONDIM R.O., SANTANA J.C.J., CHRISTAKOV E.D., FONTELES H.R.N., ALMEIDA A.B.L. 2013.

Projeto $\mu$ VANT - uma parceria DNPM/UNB para desenvolvimento e uso de $\mu$ VANTs na fiscalização de atividades minerais não tituladas. In: Simpósio Brasileiro de Sensoramento Remoto, XVI, Foz do Iguaçu: 9316-9323.

BORTOLIN, J. R. 2009. Monitoramento temporal da pluma de contaminação em aterro controlado, na cidade de Rio Claro-SP, por meio do método eletrorresistividade. Dissertação de Mestrado. Instituto de Geociências e Exatas, Universidade Estadual Paulista, 135p.

BOSCOV, M.E.G. 2012. Geotecnia Ambiental. São Paulo: Oficina de Texto, 248p.

BRASIL. Lei n. 12.305, de 2 de agosto de 2010. Diário Oficial [da] República Federativa do Brasil, Brasilia, DF, 3 ago. Seção 1, p.3.

DENTITH, M., MUDGE S. T. 2014. Geophysics for the Mineral Exploration Geoscientist. Cambridge University Press, New York, USA, 516p.

ELIS, V. R. 1999. A geofísica como ferramenta para detectar e mapear contaminação. Disponível em: < http://www.iag.usp.br/agua/geo/contaminacao_vagner.pdf $>$. Acessado em 12 de agosto de 2014
FACHIN, S.J.S., ELIS, V.R., BORGES, W.R., LAGO, A.L., USTRA, A.T., CARLOS, I.M., SANTOS, E.C., CRUZ, J.I., BIZUTI, A.M. 2007. Comparação de resultados de modelagens diretas e investigações elétricas 2D em área de depósito de resíduos urbanos.. In: 10th Congress of the Brazilian Geophysical Society, Rio de Janeiro.

GALLAS, J. D. F., TAIOLI, F., SILVA, S. M. C. P., COELHO, O. G. W., PAIM, P. S. G. 2005 . Contaminação por chorume e sua detecção por resistividade. Revista Brasileira de Geofísica (Impresso), v. 23, n. 1, p. 51-59.

GÓIS R.J. 1997. Relatório Final de Pesquisa. Curitiba: DNPM, Relatório Técnico, $29 \mathrm{p}$.

HALLOF P. G. 1957. On the interpretation of resistivity and induced polarization measurements: Cambridge, MIT, Ph. D. thesis.

LAUREANO, A.T., SHIRAIWA, S. 2008. Ensaios Geofísicos no Aterro Sanitário de Cuiabá-MT. Revista Brasileira de Geofísica, 26(2): 173-180.

LOKE, M.H. 2004. Res 2Dinv versão 3.54 for windowns 98/Me/200/NT/XP. Rapid 2D Resistivity and IP Inversion using the least - square method. Softyware manual. 133p.

MCNEIL J.D. 1980. Electrical Conductivity of Soils and Rocks, Technical note TN-5. GEONICS LIMITED. Mississauga. Canadá, 20p.

MINERAIS DO PARANÁ (MINEROPAR). Atlas Geológico comentado da Geologia e dos Recursos Minerais do Estado do Paraná. Curitiba, 2001. 
MOREIRA, C. A., AQUINO, W. F., DOURADO, J. 2007. Aplicação do método Eletromagnético Indutivo (EM) no monitoramento de contaminantes em subsuperfície. Revista Brasileira de Geofísica (Impresso), v. 25, p. 413-420.

MOREIRA C.A. \& BRAGA A.C.O. 2009. Decomposição de Resíduos Sólidos domiciliares e variações na atividade e cargabilidade. Revista Brasileira de Geofísica 27(3): 401-409.

MOURA, H. P., MALAGUTTI FILHO, W.2007 . Métodos da eletroresistividade e da polarização induzida aplicados no estudo do aterro controlado de Piracicaba - SP. Boletim de Geociências (São Paulo), v. 26, p. 35-43.

ORELLANA E. 1972. Prospeccion geoelectrica en corriente continua. Ed. Paraninfo, Biblioteca técnica Philps, Madrid, 523p.

REYNOLDS, J. M. 2003. An Introduction to applied and environmental geophysics. Jonhn Wiley \& Sons Ltda., New York, USA, 796p.

STEVANATO, R., FERREIRA, F. J. F, PEGORARO, M.; TAVARES, F. 2003. Imageamento elétrico 2D e polarização induzida na deteç̧ão de pluma de contaminação no aterro sanitário de Itajaí-SC. In: $8^{\circ}$ International Congress of The Brazilian Geophysical Society.

USTRA, A. T. 2008. Utilização dos métodos eletroresistividade e polarização induzida com aquisição de dados $3 \mathrm{D}$ para caracterização geoambiental de uma área à jusante do Aterro de Resíduos Sólidos Urbanos de Bauru-SP. Dissertação de Mestrado, Instituto de Astronomia, Geofísica e Ciências Atmosféricas, Universidade de São Paulo, 205p. 